Florida International University

FIU Digital Commons

FIU Electronic Theses and Dissertations

University Graduate School

$11-21-2014$

\title{
A State and Territorial Survey Regarding Utilization of Environmental Health Shelter Assessments during Disasters, and a Secondary Analysis of Available Shelter Assessment Data
}

Miguel A. Cruz

Florida International University, mcruz023@fiu.edu

DOI: $10.25148 /$ etd.FI14110773

Follow this and additional works at: https://digitalcommons.fiu.edu/etd

Part of the Environmental Public Health Commons, Epidemiology Commons, Occupational Health and Industrial Hygiene Commons, and the Public Health Education and Promotion Commons

\section{Recommended Citation}

Cruz, Miguel A., "A State and Territorial Survey Regarding Utilization of Environmental Health Shelter Assessments during Disasters, and a Secondary Analysis of Available Shelter Assessment Data" (2014). FIU Electronic Theses and Dissertations. 1738.

https://digitalcommons.fiu.edu/etd/1738 


\title{
FLORIDA INTERNATIONAL UNIVERSITY
}

\author{
Miami, Florida
}

\begin{abstract}
A STATE AND TERRITORIAL SURVEY REGARDING UTILIZATION OF ENVIRONMENTAL HEALTH SHELTER ASSESSMENTS DURING DISASTERS, AND A SECONDARY ANALYSIS OF AVAILABLE SHELTER ASSESSMENT DATA
\end{abstract}

A dissertation submitted in partial fulfillment of the

requirements for the degree of

DOCTOR OF PHILOSOPHY

in

PUBLIC HEALTH

by

Miguel Angel Cruz

2014 
To: $\quad$ Acting Dean Mark Williams

Robert Stempel College of Public Health and Social Work

This dissertation, written by Miguel Angel Cruz, and entitled A State and Territorial Survey Regarding Utilization of Environmental Health Shelter Assessments during Disasters, and a Secondary Analysis of Available Shelter Assessment Data, having approved in respect to style and intellectual content, is referred for your judgment.

We have read this dissertation and recommend that it be approved.

Mary Jo Trepka

Juan P. Sarmiento

Jayachandran Krishnaswamy

Date of Defense: November 21, 2014

O. Dale Williams, Major Professor

The dissertation of Miguel Angel Cruz is approved.

Acting Dean Mark Williams Robert Stempel College of Public Health and Social Work

Dean Lakshmi N. Reddi University Graduate School

Florida International University, 2014 


\section{DEDICATION}

I want to dedicate this dissertation to my entire family, who waited patiently all these years for this moment. I very much appreciate their understanding for my lack of participation in many of our family events. Thank you for all your patience and understanding during these last 5 years. 


\section{ACKNOWLEDGMENTS}

I would like to thank everyone that supported and assisted during these five years, in particular, I would like to acknowledge Dr. Jai Parkash for mentoring and helping me during the initial years in the doctoral program; I would also like to acknowledge, Dr. O Dale Williams, the Chair of my committee, for supervising this project and ensuring I stayed on track, The rest of my committee, including Dr. Thomas Mason from University of South Florida and co-chair for his expertise in the area of disasters; Dr. Janvier Gasana for providing advice regarding environmental health aspects; Dr. Mary J. Trepka for inspiring me to have career in public health; Dr. Marianna Baum for help providing the knowledge to build the foundation of what became my final proposal; Dr. Deodutta Roy and Dr. Marcus Cooke for their flexibility and commitment to make things work despite departmental changes; and finally to Darcy Cosano and Dominic Lomando for keeping the ball moving with all the administrative requirements.

I would also like to acknowledge some of my fellow students, Muni Rubens and Karina Villalba from the Department of Health Promotion and disease Prevention for their support and friendship; Stephanie Garcia, Nancy Perea, and Muhammad Baker from the Department of Biostatistics for their flexibility in accommodating my compressed schedule during the last phases of the project; and special thanks to all my colleagues at the US Center for Disease Control and Prevention for carrying with the extra load and covering work emergencies while I was out of the office at Florida International University. Also, I’d like to say a very special thanks to the National Environmental Health Association for supporting this research. 


\author{
ABSTRACT OF THE DISSERTATION \\ A STATE AND TERRITORIAL SURVEY REGARDING UTILIZATION OF \\ ENVIRONMENTAL HEALTH SHELTER ASSESSMENTS DURING DISASTERS, \\ AND A SECONDARY ANALYSIS OF AVAILABLE SHELTER ASSESSMENT \\ DATA \\ by
}

Miguel Angel Cruz

Florida International University, 2014

Miami, Florida

Professor O. Dale Williams, Major Professor

Disasters are complex events characterized by damage to key infrastructure and population displacements into disaster shelters. Assessing the living environment in shelters during disasters is a crucial health security concern. Until now, jurisdictional knowledge and preparedness on those assessment methods, or deficiencies found in shelters is limited. A cross-sectional survey (STUSA survey) ascertained knowledge and preparedness for those assessments in all 50 states, DC, and 5 US territories. Descriptive analysis of overall knowledge and preparedness was performed. Fisher’s exact statistics analyzed differences between two groups: jurisdiction type and population size. Two logistic regression models analyzed earthquakes and hurricane risks as predictors of knowledge and preparedness. A convenience sample of state shelter assessments records ( $n=116)$ was analyzed to describe environmental health deficiencies found during selected events. 
Overall, 55 (98\%) of jurisdictions responded (states and territories) and appeared to be knowledgeable of these assessments (states $92 \%$, territories $100 \%, p=1.000$ ), and engaged in disaster planning with shelter partners (states $96 \%$, territories $83 \%, p=$ 0.564). Few had shelter assessment procedures (states $53 \%$, territories $50 \%, p=1.000$ ); or training in disaster shelter assessments (states $41 \%, 60 \%$ territories, $p=0.638$ ). Knowledge or preparedness was not predicted by disaster risks, population size, and jurisdiction type in neither model. Knowledge: hurricane (Adjusted OR 0.69, 95\% C.I. 0.06-7.88); earthquake (OR 0.82, 95\% C.I. 0.17-4.06); and both risks (OR 1.44, 95\% C.I. 0.24-8.63); preparedness model: hurricane (OR 1.91, 95\% C.I. 0.06-20.69); earthquake (OR 0.47, 95\% C.I. 0.7-3.17); and both risks (OR 0.50, 95\% C.I. 0.06-3.94).

Environmental health deficiencies documented in shelter assessments occurred mostly in: sanitation (30\%); facility (17\%); food (15\%); and sleeping areas (12\%); and during ice storms and tornadoes.

More research is needed in the area of environmental health assessments of disaster shelters, particularly, in those areas that may provide better insight into the living environment of all shelter occupants and potential effects in disaster morbidity and mortality. Also, to evaluate the effectiveness and usefulness of these assessments methods and the data available on environmental health deficiencies in risk management to protect those at greater risk in shelter facilities during disasters. 


\section{TABLE OF CONTENTS}

CHAPTER

PAGE

CHAPTER I. INTRODUCTION

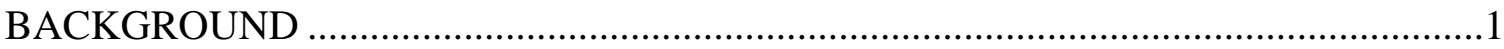

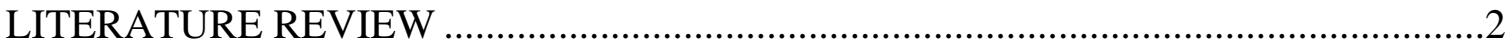

The Need for Planning for Mass Sheltering of People in Disasters ....................................2

Role and Importance of Environmental Health during Disasters .........................................

Health and Medical Vulnerabilities of Disaster Shelter Occupants.......................................9

Outbreaks of Communicable Diseases and Health Conditions in Disaster Shelters .........10

Public Health Assessments in Disaster Settings ...............................................................12

Uses of Environmental Health Assessment Data for Risk Management............................13

STATEMENT OF AIMS AND RELEVANCE ……….........................................14

RESEARCH QUESTIONS AND HYPOTHESES ................................................16

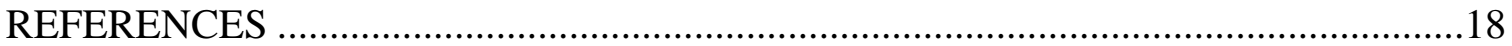

CHAPTER II. PROPOSAL CONCEPT

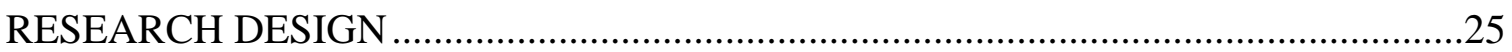

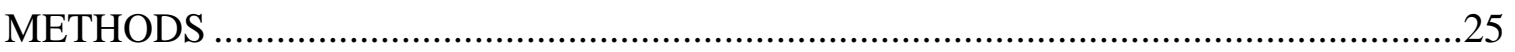

DATA ENTRY, STORAGE, MANAGEMENT, AND DISPOSITION ……………......28

HUMAN SUBJECTS PROTECTIONS AND INSTITUTIONAL REVIEW BOARD ...28

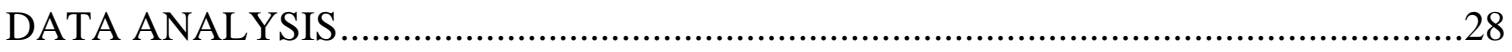

CHAPTER III. KNOWLEDGE AND PREPAREDNESS FOR USE OF

ENVIRONMENTAL HEALTH ASSESSMENTS IN SHELTERS DURING

DISASTERS: RESULTS OF THE 2013 STATE AND TERRITORIAL USE OF

SHELTER ASSESSMENTS SURVEY (STUSA)

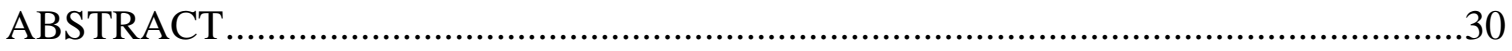

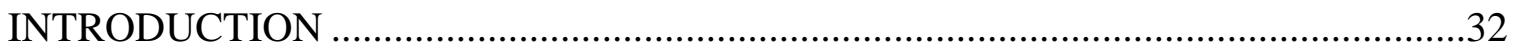

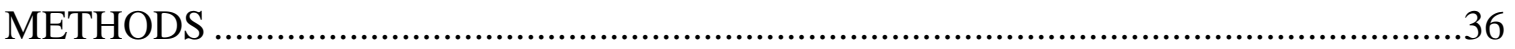

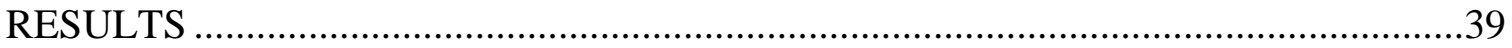

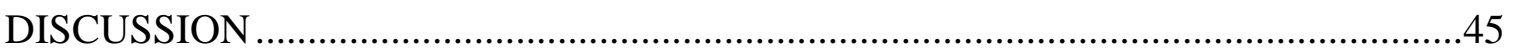

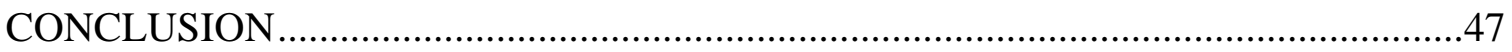

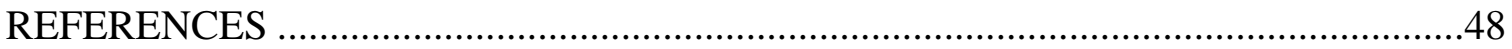

CHAPTER IV. EVALUATION OF RISKS FOR HURRICANES AND

EARTHQUAKES AS PREDICTORS OF JURIDICTIONAL KNOWLEDGE AND

PREPAREDNESS FOR ENVIRONMENTAL HEALTH SHELTER ASSESSMENTS

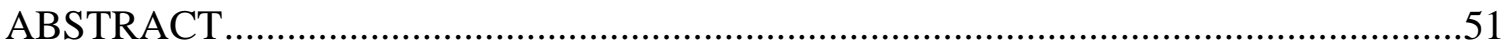

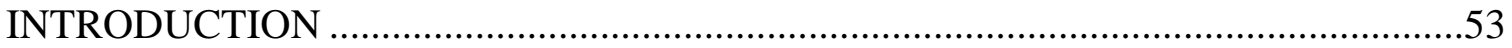

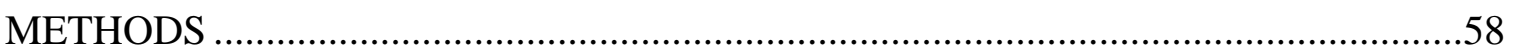

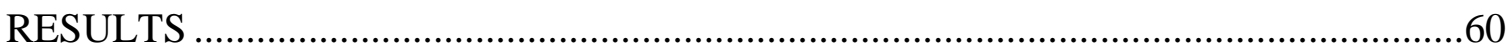

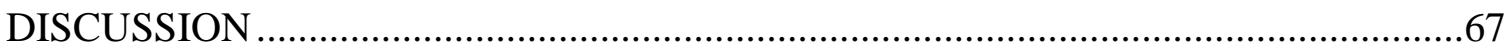




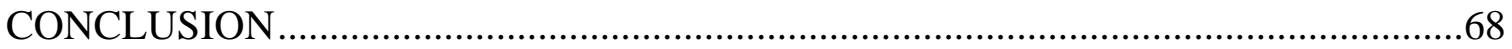

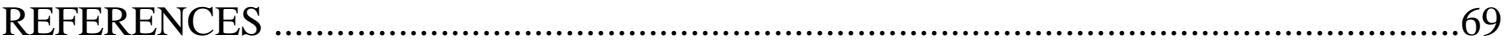

CHAPTER V. ENVIRONMENTAL HEALTH DEFICIENCIES FOUND IN DISASTER SHELTERS: A DESCRIPTIVE ANALYSIS OF STATE ENVIRONMENTAL HEALTH SHELTER ASSESSMENT DATA AVAILABLE FROM SELECTED EVENTS

ABSTRACT .74

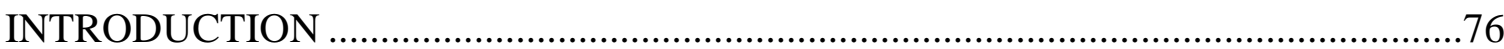

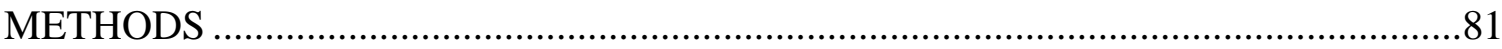

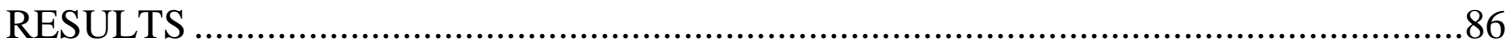

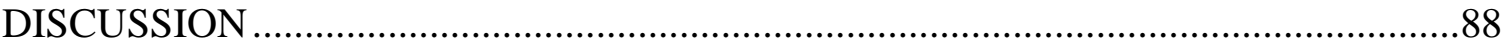

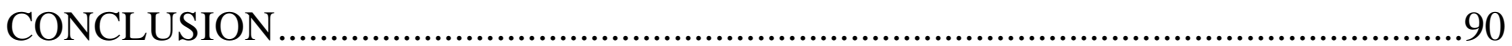

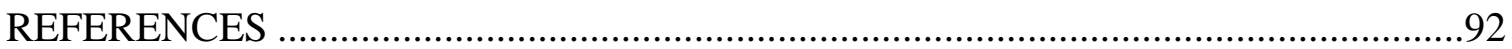

CHAPTER VI. CONCLUSIONS

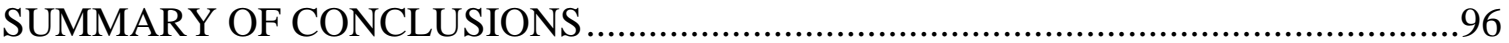

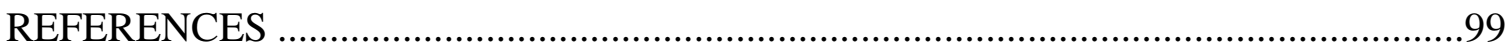

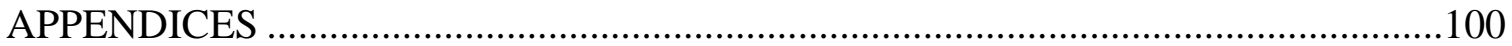

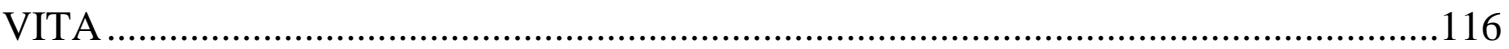




\section{LIST OF TABLES}

TABLE

PAGE

\section{CHAPTER I}

Table 1. Projected Shelter Needs versus Actual Disaster Shelter Capacity during Specific Disaster Scenarios

Table 2. Summary of Mass Care Services Provided during the 2005 Gulf Coast Hurricanes.

\section{CHAPTER III}

Table 1. Number and Percent of Responses by Jurisdiction Type and Population Size,

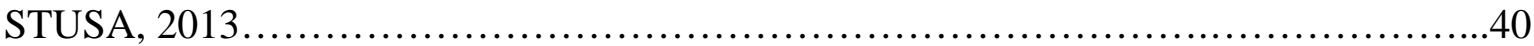

Table 2. Number and Percent of Knowledge and Familiarity with Shelter Assessment Responses by Jurisdiction Type and Population Size, STUSA, 2013.....................42

Table 3. Number and Percent of Responses about Preparedness Measures for Shelter Assessments by Jurisdiction Type and Population Size, STUSA, 2013..................43

\section{CHAPTER IV}

Table 1. Demographic Characteristics of State and Territorial Jurisdictions Respondents

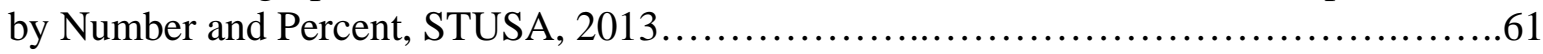

Table 2. Risk Characteristics of State and Territorial Jurisdictions Respondents by Number and Percent, STUSA, 2013.

Table 3. Number and Percent of Characteristics of Shelter Assessment Knowledge Responses According to Jurisdictional Risks, STUSA, 2013.........................64

Table 4. Number and Percent of Characteristics of Shelter Assessment Preparedness Responses According to Jurisdictional Risks, STUSA, 2013.........................64

Table 5. Knowledge Model Odds Ratios and Confidence Intervals, STUSA, 2013........65

Table 6. Preparedness Model Odds Ratios and Confidence Intervals, STUSA, 2013......66

\section{CHAPTER V}

Table 1. Number and Percent of Shelter Assessments Conducted According to Specific Disaster Events, STUSA, 2013 
Table 2. Number and Percent of Types of Shelter Facilities Assessed during Disaster

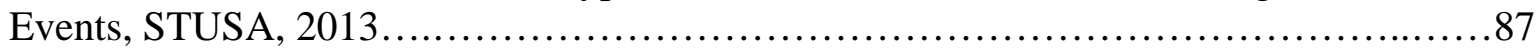

Table 3. Number and Percent of Environmental Health Deficiencies Found by Shelter

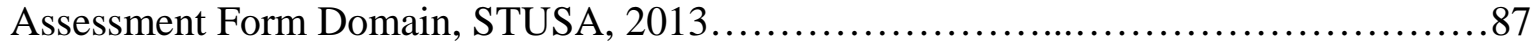

Table 4. Number of Deficiencies Found by Domain and Types of Disaster Events,

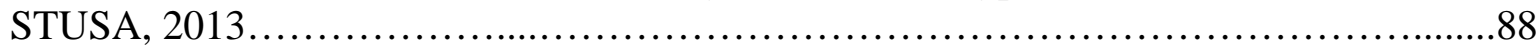




\section{LIST OF FIGURES}

FIGURE

PAGE

\section{CHAPTER I}

Figure 1. Theoretical Model of the Public Health Triad Showing the Potential Interaction between the Host, Agent and Environment in a Disaster Shelter Facility

\section{CHAPTER III}

Figure 1. Theoretical Model of the Public Health Triad Showing the Potential Interaction between the Host, Agent and Environment in a Disaster Shelter Facility ...

Figure 2. Selected Mass Care Disaster Planning Partners, by Percentage, Reported by

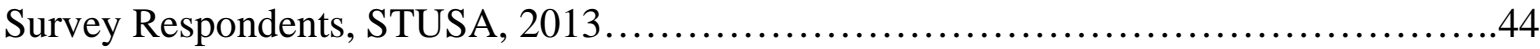

Figure 3. Selected Mass Care Disaster Drill/Exercise Partners, by Percentage, Reported by Survey Respondents, STUSA,2013.

\section{CHAPTER IV}

Figure 1. Map of US States and Territories Located in Hurricane Prone Areas...............55

Figure 2. Map of US States and Territories Located in Earthquake Prone Areas ...........56

\section{CHAPTER V}

Figure 1. Centers for Disease Control and Prevention, Shelter Assessment Tool.............82

Figure 2. Flow Diagram Describing Process for Selection of Shelter Assessment Records for Analysis..............................................................

Figure 3. Universal Shelter Assessment Form.....................................85 


\section{LIST OF ACRONYMS AND ABBREVIATIONS}

$\begin{array}{ll}\text { ARC } & \text { American Red Cross } \\ \text { CDC } & \text { Centers for Disease Control and Prevention } \\ \text { DC } & \text { District of Columbia } \\ \text { EHTER } & \text { Environmental Health Training in Emergency Response } \\ \text { FEMA } & \text { Federal Emergency Management Agency } \\ \text { FIU } & \text { Florida International University } \\ \text { G/I } & \text { Gastro Intestinal Illness } \\ \text { GRASP } & \text { Geospatial Research, Analysis, and Services Program (CDC) } \\ \text { IBM } & \text { International Business Machines } \\ \text { IRB } & \text { Institutional Review Board } \\ \text { MRSA } & \text { Methicillin-resistant Staphylococcus aureus } \\ \text { NACCHO } & \text { National Organization of City and County Health Officials } \\ \text { NEHA } & \text { National Environmental Health Association } \\ \text { NGO } & \text { Non-governmental Organizations } \\ \text { NOAA } & \text { National Oceanographic and Atmospheric Administration } \\ \text { NVOAD } & \text { National Volunteer Organizations Active in Disasters } \\ \text { PHEP } & \text { Public Health Emergency Preparedness Grant (CDC) } \\ \text { PRDOH } & \text { Statistical Package for the Social Sciences } \\ \text { R/I } & \text { RPSS }\end{array}$




\section{CHAPTER I. INTRODUCTION}

\section{BACKGROUND}

Natural disasters are characterized by damage to key infrastructure, including damage and interruption of essential public health and medical services in the affected areas. ${ }^{1}$ Population protection measures are often used in anticipation or in the aftermath of large disasters including the use of disaster shelter facilities to house persons considered at risk. Many of these displaced individuals have no place to go and need to be housed in congregate facilities such as disaster shelters or evacuation centers. Regardless of type and size, disaster shelters play a critical role in protecting people and in the survival of those affected by disasters. However, one frequent characteristic of this type of congregate setting is that shelters also bring people together in close quarters under very austere or unsanitary conditions. ${ }^{2}$

As such, during disaster conditions, monitoring environmental health conditions in facilities is important in order to reduce potential health threats to all shelter occupants. Chances of these to occur may increase as a result of direct damage to life sustaining systems of the environment that make conditions dangerous or austere to those in impacted areas. Some examples include disruption of water and basic sanitation services, carbon monoxide poisoning due proximity to portable generators. ${ }^{3}$ It has been also speculated that during disasters, outbreaks of disease, can occur as a result of a breakdown of these environmental health conditions. ${ }^{4}$

A literature review of disasters on environmental health issues in shelters was conducted. It included the review of journal articles and publications related to the role of 
environmental health in disasters; reports of outbreaks of communicable diseases and conditions in shelters; vulnerability of people living in shelters; the use of needs assessments and health risk assessments during disasters situations; and the use of environmental health assessment or inspection data used in the preventive purposes. Summaries of the most relevant findings in support of this dissertation are discussed in the next few sections.

\section{LITERATURE REVIEW}

\section{The Need for Planning for Mass Sheltering of People in Disasters}

Providing shelter services for large numbers of people displaced during large disasters could be a logistical and operational challenge for most jurisdictions. Maintenance of optimal conditions in shelter facilities can require large numbers of public health personnel who are appropriately trained on disaster response operations and the use of assessment methods, including that for environmental health shelters. A worst case scenario for any emergency management agency is an event or disaster of catastrophic magnitude that creates an unprecedented demand for disaster shelter resources. A number of catastrophic disaster events during the last few years in the US and around the world have underscored the need for better disaster preparedness and planning for housing large numbers of displaced individuals.

Disasters, particularly natural disasters like hurricanes, tornadoes, and earthquakes are unpredictable. Moreover, climate change may influence the occurrence, frequency and intensity of these events, placing larger numbers of persons at higher risk every year. ${ }^{5,6}$ Many homes today are vulnerable due to an increased exposure to natural 
hazards and because they are not built to withstand the structural stress created by high velocity winds, or water or ground-shaking. For example, earthquakes pose an imminent threat to many US states and territories. According to the US Geological Survey, at least 166 million people live in areas at high risk for earthquakes. These jurisdictions include 36 states, and all the Pacific and Caribbean territories. ${ }^{7,8}$ Another factor that justifies planning and preparation for mass-sheltering is the trend of increased urbanization and new development of coastal areas and river banks. This is an area of particular concern for coastal states and territories. One 2010 study by the National Oceanic and Atmospheric Administration (NOAA) revealed that approximately 52\% of the country's population lives within 50 miles of coastal areas. ${ }^{9}$ As a result, public health preparedness in these jurisdictions must also include planning activities for supporting large numbers of shelter facilities. In a major or catastrophic disaster, many of these individuals would require shelter and emergency housing. Table 1, shows US government projections for mass sheltering services needed to support the demand for disaster shelters during selected catastrophic disaster scenarios.

Hurricane Katrina marked a turning point for agencies that provide sheltering services, and public health in setting higher standards to ensure the protection of victims of future disasters. The response for Hurricane Katrina also highlighted the huge gaps that still exist in the management of large numbers of displaced individuals, and demonstrated what could happen if jurisdictions are caught unprepared. According to the American Red Cross (ARC), the largest provider of disaster shelter services in the United States, during the 2005 hurricane season, which included hurricanes Katrina and Rita, 
more than 1300 shelters were in operation in 27 states creating an overwhelming environmental health challenge, Table 2. During this time, over 75 million meals were prepared and distributed to those affected and deployed and a cadre of 245,000 volunteers were involved in the management of these disaster operations. ${ }^{10}$ The managing and monitoring of such a large numbers of shelter facilities (known as 'mass care”) across states during large disasters poses an operational challenge for the responsible agencies, including the Federal Emergency Management Agency (FEMA). ${ }^{11}$ In order to effectively monitor the living environment of disaster shelter occupants, shelters must be assessed on an on-going basis using tools that are readily available.

Table 1. Projected Shelter Needs versus Actual Disaster Shelter Capacity during Specific Disaster Scenarios

\begin{tabular}{llcc}
\hline \multicolumn{1}{c}{ Agency } & \multicolumn{1}{c}{ Event } & $\begin{array}{c}\text { Shelter } \\
\text { Needs* }\end{array}$ & $\begin{array}{c}\text { Actual } \\
\text { Capacity }\end{array}$ \\
\hline American Red Cross & 7.2-7.5 Earthquake in southern California & 564,113 & 84,000 \\
American Red Cross & Chemical/biological/radiological, DC & 300,000 & 13,000 \\
American Red Cross & Category 3-4 hurricane, New York City & 605,000 & 311,000 \\
Florida Emergency & Category 5 hurricane, South Florida & 885,000 & 38,000 \\
Management & & & \\
\hline Source: Mass care in Disasters, GAO-08-1175T, *per day & & &
\end{tabular}

Table 2. Summary of Mass Care Services Provided during the 2005 Gulf Coast Hurricanes

\begin{tabular}{lcc}
\hline \multicolumn{1}{c}{ Supporting } & Number & Meals \\
Organization & Sheltered & Provided \\
\hline American Red Cross & 3.4 million Overnight Stays & 52.6 Million \\
Salvation Army & 91,400 Spaces & 7.7 Million \\
Southern Baptist & N/A & 14.6 Million \\
Catholic Charities & N/A & 51 Million Lbs. \\
\hline
\end{tabular}

Source Mass care in Disasters, GAO-08-1175T

The US Centers for Disease Control and Prevention (CDC) played a crucial role in supporting and augmenting public health resources in states affected during Gulf coast 
hurricanes. After the hurricane emergency phase was complete, scientists from the CDC and other state and federal partners that participated in the public health response met to review the lessons learned and to identify areas for improvement for responding to future disaster events. One of the gaps identified was a need to create epidemiological tools for conducting public health assessments and health surveillance.

As a result of this same after-action activity, the CDC also recognized the lack of public health guidelines and recommendations in the area of disaster shelters. The CDC then initiated a number of collaborative efforts along with its disaster response partners to review and improve the inventory of disaster assessment tools, including an environmental health shelter assessment tool for shelters. Subsequently, a multi-agency workgroup of professionals from the ARC, state and local health departments, the US Department of Health and Human Services and one academic partner was assembled to develop a shelter assessment tool. This tool is known as the CDC Environmental Health Assessment Form for Shelters and was completed and released in $2008 .{ }^{12}$ Since then the initial CDC tool or modified versions have been used during a number of emergency and disaster events. Another collaborative effort between the CDC and FEMA as a result of the Katrina event was the development of a course called Environmental Health Training in Emergency Response (EHTER). This course includes a specific module on how to conduct environmental health shelter assessments using the CDC shelter assessment tool. According to the CDC, over two thousand environmental health personnel from state, local, and territorial environmental health agencies have received this training. ${ }^{13}$ 
Any event of catastrophic magnitude has the potential to quickly overwhelm local and state sheltering services. During such events, FEMA is the lead Federal agency for initiating plans for mass sheltering services. Because the Federal government alone cannot do such a task, it requires assistance from all shelter-related partner organizations, including non-governmental organizations (NGO’s). The main NGO's involved in USbased sheltering efforts are ARC and the National Volunteer Organizations Active in Disasters (NVOADs). Other NGO's actively involved include Baptist Ministries, the Salvation Army, Catholic Charities, and several other faith based organizations. However, none of these agencies has the lead responsibility for addressing public health issues, including those related to the living environment in shelters facilities. ${ }^{11}$

Regardless of the type of event, disaster survivors in shelter facilities have a humanitarian right to be treated with dignity and to be provided with a safe and healthy shelter environment that includes food, water, adequate space, security and protection from environmental health hazards. As such, public health agencies must ensure that appropriate guidance and procedures are in place to ensure that environmental health activities to assess those needs are launched without delay. Understanding what environmental deficiencies are found in disaster shelter facilities is fundamental from a health protection standpoint. Previous knowledge acquired during past outbreaks in other congregate facilities, military barracks, school dormitories, and crowded hotels had underscored the importance of maintaining appropriate levels of hygiene and sanitation in congregate facilities. Furthermore, understanding these issues would allow the public 
health team to focus their limited resources on identifying those facilities that pose the greatest risk to occupants and they ought to be considered a priority.

\section{Role and Importance of Environmental Health during Disasters}

In a general, environmental health science aims at protecting people from injury and illness by identifying risk factors, and environmental hazards that can pose risks to human health. ${ }^{14}$ Usually environmental health officers assess and inspect congregate facilities including: schools, daycare centers, adult living facilities, and food and retail establishments, in search of deficiencies that may pose a risk to the health of the public. During disasters, environmental health officers are also included as members of public health response teams responsible for monitoring environmental conditions, including those found in disaster shelters.

Disasters are complex events characterized by their ability to affect or destroy entire communities and cause significant morbidity and mortality. ${ }^{15}$ Disaster consequences include damage to life-sustaining infrastructure such as power and utilities, thus contributing to a deterioration of environmental health and sanitary conditions. ${ }^{16}$ Other disaster-related consequences include loss of hygiene, sanitation, water, and deterioration of air quality as well as accumulation of large amounts of solid waste and debris. ${ }^{17}$ After disasters, there is always a presumption that outbreaks of disease would follow. ${ }^{18}$ A general belief, however, is that the appearance of an outbreak would depend on a number of factors and characteristics of the affected populations. These factors include, access to basic needs and commodities such as safe food and water, the maintenance of adequate levels of hygiene $\&$ sanitation, access to preventive services, 
and pre-existing or endemic communicable diseases of public health importance in the impacted areas..$^{19,20,21}$

During disasters, the role of environmental health is dynamic and extends throughout all the phases of the disaster response. Usually, the environmental health teams begin working a response immediately whether the event is one that occurs suddenly (like an earthquake), or is slow-onset (such as large hurricanes or a severe drought). Environmental health officers are usually engaged in disasters as soon as communities begin the evacuation process, and stay on until recovery actions are implemented in order to ensure water, food, air, buildings and facilities are safe for the public. However, the environmental health mission is not often publicized during response operations, in contrast to other response functions such as search and rescue. ${ }^{22}$

Mass population displacements or evacuations often occur as a result of large disaster events. Individuals and entire households are asked or required to evacuate on sudden notice as a protective measure. Many individual victims of the event become displaced or homeless simultaneously, creating a sudden need for sheltering services. In the absence of a safe place to go, these homeless people often seek safe refuge in designated disaster shelter facilities for indefinite periods of time. These facilities range from small general shelters, medical shelter to mega size facilities capable of housing thousands of individuals and shelter workers.

Vulnerable populations are defined as those individuals that suffer poor physical, psychological, socio-economic or health status. These persons are presumed to possess risk factors that increase an individual's probability of becoming ill over time. ${ }^{23}$ Disaster 
victims include people from all ages and all sectors of society: children, elderly persons, individuals with chronic illnesses, disabilities, and functional needs. ${ }^{24}$ Other people requiring sheltering services include medical patients evacuated from health facilities such as, nursing homes and hospitals located in the disaster affected areas. Populations are also considered to be more vulnerable to disaster-related adverse health effects due to race, gender, education and socio-economic status. Public health agencies, particularly those with a role in prevention, have the responsibility for their safety and protection.

\section{Health and Medical Vulnerabilities of Disaster Shelter Occupants}

Disaster survivors and those providing care for them in emergency shelter facilities may be among our most vulnerable groups. ${ }^{25}$ Public health assessments during recent disasters had consistently documented the medical and mental health needs of shelter evacuees during past disaster events. For example, health needs assessments carried out to assess hurricane Katrina evacuees in Texas shelters they were mostly African-Americans from low income areas, and lacked health insurance. Large proportions of these evacuees also self-reported chronic and mental health issues, including physical and emotional stress during their stay in the shelter. Similar needs assessments conducted among hurricane Katrina evacuees in shelters in Oklahoma found that the evacuees were mostly adult African-American and males with less than a high school education, almost $63 \%$ of those interviewed had missing household members, and did not knew the conditions of their homes. In addition, $56 \%$ of the adults and $21 \%$ of children assessed had chronic health issues, and $50 \%$ of those interviewed were diagnosed as having an acute stress disorder and acute health illnessess. ${ }^{26,27}$ Another 
potential groups at risk during a disaster are be shelter workers. Many shelter workers are usually older retired members of the community, and may have their own set of chronic health and functional need issues they could also be at risk for exacerbation of injuries or illnesses, when working under austere environments. ${ }^{24}$ It is for this reason that monitoring the living environment in disaster shelters may provide an important role in preventing exacerbation of chronic illnesses or conditions, and minimizing potential mental health issues in disaster victims and those providing care for them.

\section{Outbreaks of Communicable Diseases and Health Conditions in Disaster Shelters}

Congregate facilities can be crowded and as a result of this level of human interaction within close-quarters, outbreaks of diseases and other health condition can occur. Figure 1, shows the potential interaction between the environment, hosts, and agent and how these risk factors may combine to affect the health of shelter occupants. Individuals with chronic health issues or those who may have low or no immunity to certain opportunistic disease agents could become exposed to infectious agents or environmental hazards under these austere environmental conditions. As a result, outbreaks of communicable disease or condition or injuries may occur.

Congregate facilities such as college dormitories, nursing homes, and military barracks, have been implicated previously as settings for outbreaks of communicable disease, even in non-disaster situations. ${ }^{28}$ There is well documented evidence that outbreaks have occurred in shelter facilities during past disasters. For example, during the aftermath of Hurricane Hugo, the Puerto Rico Department of Health (PRDOH) reported cases of respiratory illness and head lice in shelters. In addition, PRDOH identified 
outbreaks of GI illness in approximately 22\% of the emergency shelters facilities in operation. $^{29}$

- Infectious agents

- Novel or new disease

- Air pollutants

- $\quad$ Other environmental hazards (e.g., CO)

- $\quad$ Crowded living conditions

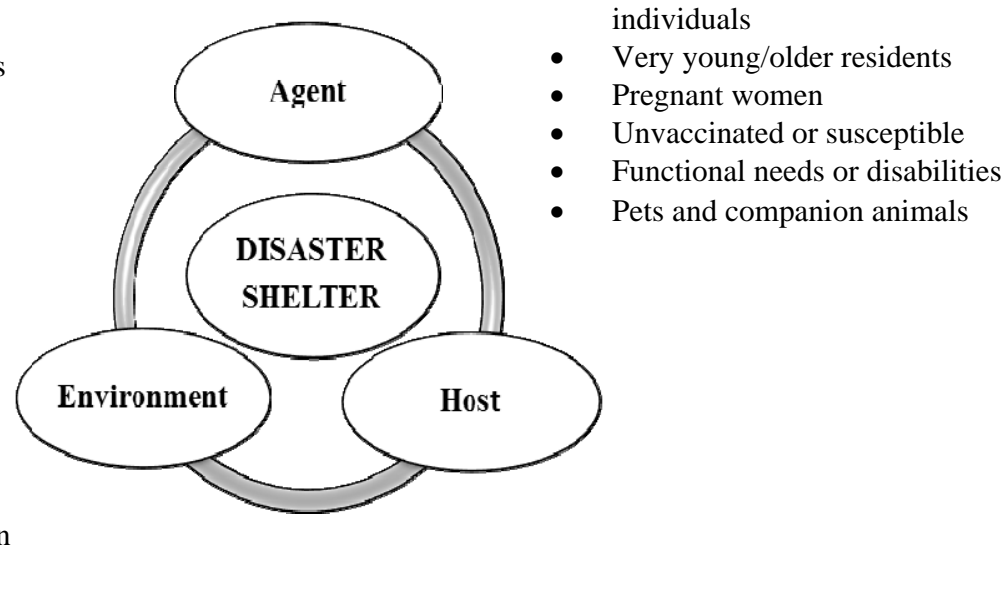

- $\quad$ Limited hygiene \& sanitation

- $\quad$ Austere conditions

Figure 1. Theoretical Model of the Public Health Triad Showing the Potential Interaction between the Host, Agent and Environment in a Disaster Shelter Facility

During the aftermath of Hurricane Katrina in 2005, outbreaks of noroviruses were reported among evacuees living in shelters located in the states of Colorado, Georgia, Louisiana, Mississippi, Tennessee, and Texas. According to the CDC, gastrointestinal illness was the most common acute disease complaint reported among Katrina evacuees living in shelters. Laboratory tests conducted involving some of the ill shelter residents' detected presence of norovirus and other illness-causing pathogens like salmonella, nontoxigenic Vibrio cholerae, Vibrio vulnificus, and Vibrio parahemolyticus. ${ }^{30}$ A large cluster of methicillin resistant Staphylococcus aureus (MRSA) was also detected among children and several adults in a Texas shelter facility daycare area. ${ }^{31,32}$ During Hurricanes Ike and Gustav, public health surveillance activities in ARC shelters revealed that the most chief complaints in shelters involved exacerbation of chronic conditions, and acute 
illness which included respiratory (R/I) and gastrointestinal illness complaints (G/I). ${ }^{33}$ Outside the US outbreaks of watery diarrhea, measles, cholera, respiratory infections, and pneumonia have been reported also in shelters. ${ }^{34,35,36,37,38}$

Shelter residents are a very special group of individuals. In some cases they are the only survivors of a community destroyed by a disaster. As such, they have a humanitarian right to be treated fairly and with dignity and respect. ${ }^{39}$ The importance of shelters and in particular, environmental health issues has been recognized and the CDC has made funding available to states under the CDC Public Health Emergency Preparedness cooperative agreement or PHEP to develop plans and collaborations with shelter partners for supporting shelter assessment activities during disasters. ${ }^{40}$

\section{Public Health Assessments in Disaster Settings}

Public health assessments are valid epidemiological methods used in disasters, and are recognized as useful tools for obtaining timely, reliable, and accurate information about the health needs of the affected populations. ${ }^{41}$ Disaster assessments are also used to evaluate health status, mortality, medical care needs, food and nutrition, sanitation, housing damage, shelter type, and access to lifesaving systems such as electricity, communications, and transportation. ${ }^{42}$

Disaster assessments are considered a priority during disasters, as this data provides useful information for determining the extent of the effects of the event, as well as the immediate priorities of the affected populations. ${ }^{43,44}$ By as early as 1992, US public health agencies embraced the use of health needs or rapid need assessment methodologies, and used them consistently since the aftermath of Hurricane Andrew in 
Florida and Louisiana. ${ }^{45}$ Since then, public health assessments in disasters have been used in a number of disaster events in the U.S. including Tropical Storm Allison in 2001, Hurricanes Katrina in 2005, Ike 2008 and a number of other emergencies and events. ${ }^{46,47,48,49}$ Needs assessments methods have also been used in international responses to assess the environmental health needs of displaced persons and shelter facilities, examples of which include the 1999 earthquake in Turkey, the 1999 Chi-Chi earthquake in Taiwan, and the 2004 Tsunami in Indonesia. .0,51 $^{2}$

\section{Uses of Environmental Health Assessment Data for Risk Management}

In the past, the results of environmental health inspections and assessments have been used to study associations between environmental health deficiencies found, and risk of outbreaks of disease in congregate facilities. These facilities included cruise ships, restaurants, water facilities, and the workplace. For example, the CDC routinely uses the results of environmental health sanitation inspections to reduce the occurrence of outbreaks, and to identify unsafe sanitation practices in passenger cruise ships. ${ }^{52}$ Others have used data available from the results of restaurant inspections modeled after the US Food and Drug Administration Food Code to ascertain the risk for outbreaks in restaurant facilities and to develop systems for inspecting food facilities..$^{53,54,55,56}$

For example, during preparations for the 2004 Olympic Games in Athens, Greece, data from the assessments of water supply systems were used to predict the contamination associated with certain pathogens in the water systems located in Olympic Games venues. ${ }^{57}$ Environmental health data has been used also in occupational health 
settings to predict rates of absenteeism on the workplace including health care

facilities. $^{58,59}$

\section{STATEMENT OF AIMS AND RELEVANCE}

To date, no one has described the utilization of environmental health shelter assessment methods in US states and territories. As a result, there are not known surveys that show how prevalent, trained, or how engaged in planning these jurisdictions are in their preparedness for evaluating the conditions of these facilities during disasters. Furthermore, the environmental health hazards and deficiencies found in disaster shelters have not been evaluated or described across disasters. Currently, there are gaps in information about what environmental health factors or deficiencies are found in disaster shelters. This may be accomplished using assessment data that is available in various jurisdictions that use these assessments. Furthermore, these data may also provide additional insight as to what prevention efforts are more effective in protecting the health of shelter occupants during disasters.

There is a need to address this gap by analyzing data across various environmental health domains or areas contained in the shelter assessment tools like food, water, hygiene and sanitation among others. Once a better understanding of which environmental health factors are more prevalent then practitioners will be in better position to use data that already exists from these assessments in the development of standard tools, procedures, public health disaster guidelines or recommendations for shelter that are based on actual assessment findings and documentation. Current disaster or evacuation shelter guidelines are known to be based on anecdotal information and 
from extrapolating public health findings from similar assessments in other congregate settings. Furthermore, these disaster shelter or mass care guidelines had never been validated and their efficacy in preventing illness has never been demonstrated.

The potential for outbreaks of disease and other conditions in congregate facilities, other than shelters, is well documented. However this is not the case for disaster shelters since the potential triggers or causal conditions in disaster shelters have not been well documented. Disaster shelters are not much different from other congregate facilities, however it is difficult to extrapolate findings from those settings to the disaster shelters because, in contrast to other facilities (barracks, dormitories), disaster shelters are frequently associated with relatively more austere environmental conditions. This research has a potential to stimulate others to investigate the shelter living environment in order to answer these epidemiological questions 1) What is the degree of knowledge about environmental health shelter assessments in US jurisdictions 2) How prepared jurisdictions are to utilize these assessments during disasters 3) Are there any differences with respect to knowledge and preparedness based on disaster risk characteristics 4) Who is using them, and if assessments are used, what are the environmental deficiencies or conditions are commonly found in facilities. Therefore, the aims of this study are:

- Gain additional information regarding the prevalence of shelter assessments among US jurisdictions.

- Describe how many jurisdictions are knowledgeable about these assessment methods and whether there are potential differences across jurisdictions. 
- Describe jurisdictional preparedness for using environmental health shelter assessments during disasters.

- Explore potential jurisdictional risks that may predict better knowledge and preparedness for these assessments.

- Identify main domains of environmental health (facility, food, water, sanitation, and waste) where deficiencies have been found in shelter facilities using available data from jurisdictions.

- Describe environmental health deficiencies found across subdomains.

- Describe environmental health deficiencies found across types of disasters.

- Describe potential shelter recommendations for improvement of disaster shelter assessments methods based on our findings.

- Develop three manuscripts for potential publication describing the above research work.

\section{RESEARCH QUESTIONS AND HYPOTHESES}

Phase one: Our aim is to answer the following research questions using STUSA survey results:

1. How prevalent are these assessment methods in US state and territorial jurisdictions?

2. How knowledgeable are these jurisdictions in general about disaster shelter assessment methods?

3. How prepared are these jurisdictions in general to carry out these shelter assessments during disasters? 
Hypothesis 1. Significant variability exists in knowledge, familiarity, training, and preparedness between jurisdictions and characteristics such as type and population size. Hypothesis 2. Jurisdictions with specific factors, such as risk for hurricanes or earthquakes or both risks are more knowledgeable of shelter assessments than those that have no such risks?

Hypothesis 3. Jurisdictions with specific factors, such as risk for hurricanes or earthquakes or both risks are more prepared to conduct shelter assessments than those that have no such risks?

Phase two: Our objective is to answer the following research questions using data available on shelter assessments:

1. Will the number and type of environmental health deficiencies in the shelters vary according to the type and severity of disaster?

2. Which type environmental health domains showed the greatest number of deficiencies? 


\section{REFERENCES}

1. World Health Organization. Communicable diseases following natural disasters. Risk assessment and priority interventions. Retrieved from:

http://www.who.int/diseasecontrol_emergencies/guidelines/CD_Disasters_26_06.pdf ?ua=1. Accessed April 2012.

2. Humanitarian charter and minimum standards in disaster response 2011 edition. Sphere Project. Retrieved from: http://www.sphereproject.org/handbook/. Accessed March 20, 2013.

3. PAHO. Environmental health management after natural disasters. PAHO Scientific Publication, No. 430. Retrieved from: http://www.disasterinfo.net/watermitigation/i/publications/Envhealth/index_en.html. Accessed April 2012.

4. Ivers LC, Ryan ET. Infectious disease of severe weather-related and flood-related natural disasters. Current Opinion in Infectious Diseases 2006;19:408-414.

5. Greenough G, McGeehin M, Bernard SM, Trtanj J, Riad J, Engelberg D. The Potential Impacts of Climate Variability and Change on Health Aspects of Extreme Weather Events in the United States. Environ Health Perspect 2008. 109(2):191-198.

6. Haines A, Patz JA. Health effects of Climate Change. JAMA2004; 291:99-103

7. Personal communication with Dr. Bill Leith (USGS) about unpublished data, 2013.

8. USGS. United States National Seismic Hazard Maps. Retrieved from: http://pubs.usgs.gov/fs/2008/3017/pdf/FS08-3017_508.pdf. Accessed March 2012.

9. Carpender SK, Campbell PH, Quiram BJ, Frances J, Artzberger JJ. 2006. Urban evacuations and rural America: lessons learned from hurricane Rita. Public Health Reports 121:775-779.

10. GAO. Voluntary organizations in disasters. FEMA should more fully assess organizations mass care capabilities and update the Red Cross role in catastrophic events. September 18, 2008. Government Accountability Office, Retrieved from: http://www.gao.gov/products/GAO-08-823. Accessed October, 2013.

11. National Response Framework. Retrieved from: https://s3-us-gov-west1.amazonaws.com/dam-production/uploads/20130726-1914-250451246/final_national_response_framework_20130501.pdf. Accessed July 2014.

12. CDC. Emergency Preparedness and Response. CDC Shelter Assessment Tool. Retrieved from: http://www.bt.cdc.gov/shelterassessment/. Accessed December 2012. 
13. Environmental Health Training in Emergency Response (EHTER). Retrieved from: http://www.cdc.gov/nceh/ehs/eLearn/EHTER.htm. Accessed November 20, 2013.

14. New Perspectives on environmental health: the new approval of new definitions. NEHA News. Journal of Environmental Health 2013;73:72-73.

15. Noji E. The Public Health Consequences of Disasters. Prehospital and Disaster Medicine 2000 Oct-Dec;15:147-157.

16. Harvey PA, Reed RA. Planning environmental sanitation programmes in emergencies. Disasters 2005;29:129-151.

17. PAHO. Environmental Health Management after Natural Disasters 1983.

18. Waring SC, Brown BJ. The Threat of Communicable Diseases Following Natural Disasters: A Public Health Response. Disaster Management and Response 2005;3:4147.

19. Watson JT, Gayer M, Connolly MA. Epidemics after Natural Disasters. Emerging Infectious Diseases 2007;13:1-5.

20. Ivers LC, Ryan ET. Infectious Disease of Severe Weather-Related and Flood-Related Natural Disasters. Current Opinion Infectious Diseases 2006;19:408-414.

21. Aghababian RV. Infectious diseases following disasters. Annals of Emergency Medicine 1992;21:362-367.

22. Eldridge D, Teakate TD. The role of environmental health in disaster management: an overview and review of barriers and facilitators for action. Reviews on Environmental Health 2006;21:291-294.

23. Aday LA. Health status of vulnerable populations. Annual Review of Public Health 1994;15:487-509.

24. Brodie M, Weltzioen E, Altman D, Blendon J, Benson JM. Experiences of hurricane Katrina evacuees in Houston shelters: implications for future planning. American Journal of Public Health 2006;96:1402-1408.

25. Patton-Levine JK, Vest JR, Valadez AM. Caregivers and families in medical special needs shelters: an experience during hurricane Rita. American Journal of Disaster Medicine 2007;2:81-86.

26. Greenough G, Lappi MD, Hsu EB, Fink S, Hsieh Y, Vu A, Heaton C, Kirsch TD. Burden of disease and health status among hurricane Katrina displace persons in shelters: a population-based cluster sample. Annals of Emergency Medicine 2008;51:426-432. 
27. Rodriguez SR, Tocco JS, Mallonee S, Smithee L, Cathey T, Bradley K. Rapid needs assessment of hurricane Katrina evacuees-Oklahoma, September 2005. Prehospital and Disaster Medicine 2006;21:390-395.

28. Brundage JF, Scott RM, Lednar WM, Smith DW, Miller RN. Building associated risk of febrile acute respiratory disease in Army trainees. JAMA 1988;259:2109-2112.

29. CDC. Epidemiologic Notes and Reports Surveillance of Shelters after Hurricane Hugo-Puerto Rico. MMWR 1990;39:41-47.

30. CDC. Infectious disease and dermatologic conditions in evacuees and rescue workersafter hurricane Katrina-Multiple states, August-September, 2015. MMWR 2005;54:961-964.

31. Cookson ST, Soetebier K, Murray EL, Fajardo GC, Hanzlick R, Cowell A, Drenzek C. Internet-based morbidity and mortality surveillance among hurricane Katrina evacuees in Georgia. Preventing Chronic Disease 2008;5:A133.

32. Yee EL, Palacio H, Atmar RL, Umair S, Kilborn C, Faul M, Gavahan TE, Feigin RD, Versalovic J, Neill F, Panlilio AL, Miller M, Spahr J, Glass RI. Widespread outbreak of norovirus gastroenteritis among evacuees of hurricane Katrina residing in a large "Mega Shelter" in Houston, Texas: lessons learned for prevention. Clinical Infectious Diseases 2007;44:1032-1039.

33. Noe RS, Schnall AH, Wolkin AF, Podgornik MN, Wood AD, Spears J, Stanley SA. Disaster-related injuries and illnesses treated by American Red Cross Disaster Health Services during Hurricanes Gustav and Ike. Southern Medical Journal 2013;106:102108.

34. World Health Organization. Acute water diarrhea outbreak. Weekly Morbidity and Mortality Report. 2005;1:6. Retrieved from: http://www.who.int/hac/crises/international/pakistan_earthquake/sitrep/FINAL_WM MR_Pakistan_1_December_06122005.pdf.

35. CDC. Surveillance in evacuation camps after the eruption of Mt. Pinatubo, Philippines. MMWR 1992;41:9-12.

36. PAHO. Health response to the earthquake in Haiti, January 2010: Lessons to be learned for the next massive sudden onset disaster. Retrieved from: http://reliefweb.int/sites/reliefweb.int/files/resources/Full_Report_3342.pdf. Accessed April 2012.

37. The Wall Street Journal. Illness surge among quake victims. Retrieved from: http://online.wsj.com/article/SB10001424052748703907004576278620034100668.ht ml. Accessed April 2012. 
38. Brennan RJ, Rimba K. Rapid health assessment in Aceh Jaya district, Indonesia, following the December 26 tsunami. Emergency Medicine Australasia 2005;17:341350.

39. The Sphere Project. Humanitarian charter and minimum standards in disaster response 2011 edition. Retrieved from: http://www.sphereproject.org/handbook/. Accessed March 2012.

40. CDC. 2011 PHEP Cooperative Agreement Guidance/Budget Period 11. Program Announcement TP11-1101CONT11-FY 2011. Retrieved from: http://www.cdc.gov/phpr/coopagreement.htm. Accessed April 2012.

41. Malilay J. Public health assessments in disaster settings: recommendations for a multidisciplinary approach. Prehospital and Disaster Medicine 2005;15:167-172.

42. Korteweg HA, Bokhoven IV, Grievink L. Rapid health and needs assessments after disasters: a systematic review. BMC Public Health 2010;10:295.

43. Malilay J, Henderson A, McGeehin M, Flanders D. Estimating health risks from natural hazards using risk assessment and epidemiology. Risk Analysis 1997;17:353358.

44. Malilay J, Hermann M, Perrott D, Wolkin AF, Schnall AH, Podgornik MN, Cruz MA, Horney JA, Zane D, Riesman R, Greenspan JR, Thoroughman D, Anderson HA, Wells EV, Simms EF. The role of applied epidemiology methods in the disaster management cycle. American Journal of Public Health 2014;104:2092-2102.

45. Hlady WG, Quenemoen LE, Armenia-Cope RR, Hurt KJ, Malilay J, Noji EK, Wurm G. Use of a modified cluster sampling method to perform rapid needs assessment after a hurricane Andrew. Annals of Emergency Medicine 1994;23:719-725.

46. CDC. Tropical storm Allison rapid needs assessment-Houston, Texas, June 2001. MMWR 2002;51:365-369.

47. Greenough PG, Kisrh TD. Public health response-assessing needs. New England Journal of Medicine 2005;353:1544-1546.

48. CDC. Rapid needs assessment of two rural communities after hurricane Wilma-Hendry County, Florida, November 1-2,2005. MMWR 2006;55:429-431.

49. CDC. Hurricane Ike rapid needs assessment---Houston, Texas, September 2008. MMWR 2009;58:1066-1071.

50. Daley WR, Karpati A, Sheik M. Needs assessment of the displaced population following the August 1999 earthquake in Turkey. Disasters 2001:25:67-75.

51. Chen KT, Chen WJ, Malilay J, Twu SJ. The public health response to the Chi-Chi earthquake in Taiwan, 1999. Public Health Reports 2003;118:493-499. 
52. Cramer EH, Blanton CJ, Otto C. Shipshape: sanitation inspections on cruise ships. 1990-2005, Vessel Sanitation Program, Centers for Disease Control and Prevention. Journal of Environmental Health 2008; 70:15-21.

53. FDA. Food Code. US Department of Health, Public Health Service 2009. Retrieved from:http://www.fda.gov/downloads/Food/FoodSafety/RetailFoodProtection/FoodCo de/FoodCode2009/UCM189448.pdf. Accessed April 2012.

54. Irwin K, Ballard J, Grendon J, Kobayashi J. Results of routine inspections can predict outbreaks of food-borne illness: the Seattle-King County experience. American Journal of Public Health 1989; 79:586-590.

55. Cruz MA, Katz DJ, Suarez J. An assessment of the ability of routine restaurant inspections to predict food-borne outbreaks in Miami-Dade County, Florida. American Journal of Public Health 2001; 91:821-823.

56. Jones TF, Pavlin BI, LaFleur JB, Ingram L, Schaffner W. Restaurant inspection scores and food-borne disease. Emerging Infectious Diseases 2004;10:688-692.

57. Hadjichristodoulou Ch, Goutziana G, Mouchtouri V, Kapoula Ch, Kosntantinidis A, Velonakis E, Vatopoulos A, Kremastinou J. Evaluation of standardized scored inspections for Legionnaires disease prevention during the Athens 2004 Olympics. Epidemiology of Infections 2006;134:1074-1081.

58. Lindell MK. Occupational safety and health inspection scores predict rates of workers lost-time injuries. Accident: Analysis and Prevention 1997;5:571-1997.

59. Valenti AJ, Jecker MD. OSHA inspections. Workplace inspections. Infection Control \& Hospital Epidemiology 1995;16:478-482. 


\section{CHAPTER II. PROPOSAL CONCEPT}

\section{RESEARCH DESIGN}

This dissertation was conducted in two phases or activities as follows: phase one was a cross-sectional survey of all US State and Territorial Jurisdictions; phase two was a descriptive analysis of secondary data available on shelter assessments conducted by state and territorial jurisdictions during emergencies or disasters.

\section{METHODS}

Phase one: A Jurisdictional Survey to Assess Knowledge, Awareness, and Utilization of Environmental Health Shelter Assessments during Disasters

A survey of state and territorial environmental health departments directors or their designees $(\mathrm{N}=56)$ was conducted in order to establish the prevalence of use of shelter assessments, A list of environmental health directors was created using information available to various public health organization websites including the National Association of City and County Health Officials, and the National Environmental Health Association (NEHA). In addition to providing information about environmental health programs, NEHA also provided a letter of support that became part of the introductory package (Appendix 1). All US states and territories were invited to participate. A full survey package included invitations to participate in an on-line or mailin survey and was sent via email to environmental health directors in all 50 states, the District of Columbia, and two US Caribbean and three US Pacific Territories (American Samoa, Guam, Northern Mariana Islands, Puerto Rico, and the US Virgin Islands).

The package included instructions on where and how to access the survey on-line (Appendix 2). A second communication was sent two weeks after the initial invitation. 
This time the materials included a link to the live on-line survey; an address where to send a soft copy of the survey by e-mail; an address where to mail the survey; other instructions and contact information of the survey organizers in case participants had questions; and the letter of support from NEHA (Appendix 3) and a copy of the survey tool (Appendix 4). For operational and identity purposes the survey was named the State and Territorial Shelter Assessment Utilization survey (STUSA).

The STUSA survey tool consisted of an introduction where questions were asked about the respondent affiliation. There were a total of 15 main subject questions and 13 follow up questions for a total of 28 questions to answer. The survey tool was divided into five domains: knowledge and familiarity about shelter assessments; procedures and training; utilization of assessment tools; participation in planning and exercises; and respondent feedback. Questions on "knowledge and familiarity” were aimed at gaining understanding of the respondents' knowledge with shelter assessments and tools content. Questions related to “procedures and training questions” evaluated the extent of development for operational procedures for conducting assessments, defined roles and expectations of the agency as the assessor entity, and identified training received in assessments. The "utilization” questions assessed the experiences of the jurisdiction in using the assessments. The questions related to "participation in planning and exercises" were aimed at establishing level of involvement in planning and readiness (exercise/drills) with shelter partners.

Before the survey was launched in the spring of 2013, it was first piloted in two states and one territorial jurisdiction. In addition, feedback on the survey was obtained 
from two experts in the area of environmental health at the US Centers for Disease Control and Prevention. The on-line survey platform was built on Qualtrics, accessed through Florida International University (FIU). After the surveys were deployed, followups occurred after two weeks if no response was received. The protocol established that if no response was received after five attempts, a call will be made to the jurisdiction inquiring the reasons why the particular jurisdiction was not interested (Appendix 5). Phase two: A Secondary Data Analysis of Shelter Assessment Data Sets Obtained During this last phase of the project, jurisdictions were contacted once again and invited to collaborate in the research by making data available on environmental health shelter assessments. The initial data call was issued for all the 55 state and territorial jurisdictions that previously responded to the STUSA survey in the initial phase of the project. This call for data lasted from May - August 2014. Data sets received underwent an evaluation process for inclusion or exclusion criteria of the study. Inclusion Criteria:

- The shelter's main information blocks on the survey were completed

- The shelter assessor organizations was known

- Initial assessment was included

- No repeated assessments of the same shelter during a same event Exclusion Criteria:

- Incomplete or missing facility information

- Shelters of last resource (people seeking shelter or refuge in non-designated shelter facilities or encampments) 


\section{DATA ENTRY, STORAGE, MANAGEMENT, AND DISPOSITION}

All survey results were entered and reviewed for completeness and consistency. Subsequently, all survey forms received were stored in a secured database at FIU. Paper survey forms received were subsequently scanned and electronically stored. A back up file was created and maintained under secure storage that was only accessible by biometric access. No one except the primary investigator (PI), and statisticians working with the project received access to the data files. A log was maintained for all data sets received from the state and local jurisdictions. State and agency identification information was not reported and data was analyzed as aggregates. All the data was analyzed using IBM SPSS Statistics version 21.

\section{HUMAN SUBJECTS PROTECTIONS AND INSTITUTIONAL REVIEW BOARD}

The Florida International University Institutional Review Board (IRB) granted an IRB protocol exemption in May 2013 (Appendix 6).

\section{DATA ANALYSIS}

Phase one: A Jurisdictional Survey to Assess Knowledge, Awareness, and Utilization of Environmental Health Shelter Assessments during Disasters

Data analysis was performed using IBM SPSS Statistics 21. Frequencies and descriptive analysis were performed to describe knowledge, usage, and preparedness of shelter assessment in jurisdictions. Jurisdictions were categorized based on population size and jurisdiction type. Cross tabulations were applied to compare jurisdictions with knowledge and preparedness. Further analyses were performed to evaluate jurisdictional knowledge and preparedness in areas that have specific or known risks for disasters such 
as hurricanes and earthquakes. Univariate and multivariate analysis was performed to establish which variables predicted jurisdictional knowledge and preparedness. All tests conducted throughout the study were considered statistically significant if $p<0.05$.

Phase two: Secondary Analysis of Shelter Assessment Data

Secondary data analyses for this study were conducted using IBM SPSS Statistics

version 21. Descriptive statistics and frequencies were used to describe the variables on the shelter assessment tools domain across disaster and facility type. 


\title{
CHAPTER III
}

KNOWLEDGE AND PREPAREDNESS FOR USE OF ENVIRONMENTAL HEALTH

ASSESSMENTS IN SHELTERS DURING DISASTERS: RESULTS OF THE 2013

STATE AND TERRITORIAL USE OF SHELTER ASSESSMENTS SURVEY

(STUSA)

\begin{abstract}
Background: To date, no studies have been conducted to ascertain how widely environmental health disaster shelter assessments methods are or how they are utilized in the US states and territories. Environmental health assessments evaluate environmental conditions (hygiene, environmental and occupational hazards) of shelter occupants to ensure their safety and wellbeing. This survey determined the prevalence of environmental health assessments, and establishing how knowledgeable and prepared jurisdictions are about these disaster assessment methods.
\end{abstract}

Methods: In 2013 a cross-sectional survey of US state and territorial ( $\mathrm{N}=56)$ environmental health department directors was conducted. The survey is known as the State and Territorial Utilization of Shelter Assessment (STUSA).

Results: Overall, 55 (98\%) of the jurisdictions responded and completed the survey. Of those, $92 \%$ of state jurisdictions and $100 \%$ of territories and the D.C. were found to be knowledgeable about shelter assessments methods $(p=1.000)$. With regards to preparedness, about $40 \%$ of states and $60 \%$ of territories reported having formal training on shelter assessments $(p=0.638)$ and having operational procedures for shelter assessments; states 53\% versus territories 50\% $(p=1.000)$. 
Discussion: High levels of knowledge and familiarity with environmental health shelter assessment methods were reported. However, jurisdictions also reported low levels of training and processes for operationalizing these assessments during disasters. As a result, there is a need to conduct additional research to understand how jurisdictional barriers or factors affect the implementation of shelter assessments activities’ in disasters, including program support and resource limitations, perception of disaster risks, past experiences in disasters.

Conclusion: Environmental health assessments can provide fast and useful information during disaster. Jurisdictions should consider using these assessment methods for gaining better insights into the shelter facilities living environment. Also, better effort must be placed in providing disaster training to the public health workforce that includes disaster assessments. 


\section{INTRODUCTION}

Disasters, whether natural or man-made, are complex events that can affect lifesaving and life sustaining systems in the United States and its territories. During the period of 2003-2013, at least 269 known US disasters that were recorded by the Centre for Research on the Epidemiology of Disasters resulted in at least five hundred fatalities, left another ten thousand injured, and affected over 21 million people. ${ }^{1}$ The austere environment created by disaster conditions could jeopardize the health of individual including those occupying disaster shelters. Protecting the health of persons affected by disasters is an important priority in any disaster response. Amidst the chaos and difficult conditions, there is a need for quicker and simpler ways for gaining situational awareness about the status and needs of the affected populations. ${ }^{2}$

Public health disaster assessments, also known as rapid needs assessments, are epidemiological, statistical, and anthropological methods that allow rapid collection, analysis, and dissemination of event information for decision making and resource prioritization. $^{3}$ The types of information captured by these assessments include health status, hygiene, sanitation, and other basic human needs or services. ${ }^{4,5,6,7,8}$ One early example of disaster assessment usefulness in a large domestic disaster occurred during the response to the aftermath of hurricane Andrew in Florida in 1992. Since then other variations of disaster assessment tools have been developed and deployed during all hazards responses. Despite improvements in disaster assessments, there are still challenges in disaster assessment operations among them a lack of standardization of assessment tools, standard operational procedures and tools, timeliness for reporting 
findings, and coordination and sharing of information between the various assessments entities in theater. ${ }^{10}$

Population protection measures, often used in anticipation of or in the aftermath of large disasters, frequently include the use of disaster shelter facilities to house persons considered at risk. Many of these displaced individuals have no place to go and need to be housed in congregate facilities like disaster shelters that are put in place immediately after disaster impact. Shelters play a critical role in protecting people and in the survival of those affected by disasters. ${ }^{11}$ One characteristic of this particular type of congregate setting, is that they may bring people together under what are often very austere or sometimes even unsanitary conditions. ${ }^{12}$ Furthermore, many of these individuals often arrive at the shelters with medical, mental health, or other functional needs such as physical, sensory, cognitive or intellectual disabilities. ${ }^{13}$ Figure 1, depicts the potential interaction that can occur in a disaster shelter facility. One potential scenario is the introduction of a communicable disease or condition that could rapidly spread among most of the vulnerable shelter occupants living under these austere conditions.

The task of managing and monitoring large numbers of shelter facilities across localities or several states during large disaster events frequently poses an operational challenge for shelter operators. For example, at the peak of the sheltering effort for hurricanes Katrina and Rita, more than 1,300 disaster shelters were in operation in 27 states. ${ }^{14}$ In order to be able to effectively monitor the living environment of disaster shelter occupants, shelters must be assessed during events. This can be accomplished using standard tools and methods, like environmental health shelter assessments. 
According to the National Response Framework, the US government's blueprint for responding to emergencies and disasters, agencies such as FEMA and the ARC are in charge of most shelter operations, also known as “mass care activities”. ${ }^{15}$ Public health teams support the lead agencies by providing preventive services to ensure the health and safety of those affected in disaster shelters or any other congregate setting used for housing survivors or responders.

- Infectious agents

- Novel or new disease

- Air pollutants

- Other environmental hazards (e.g., CO)

- Crowded living conditions

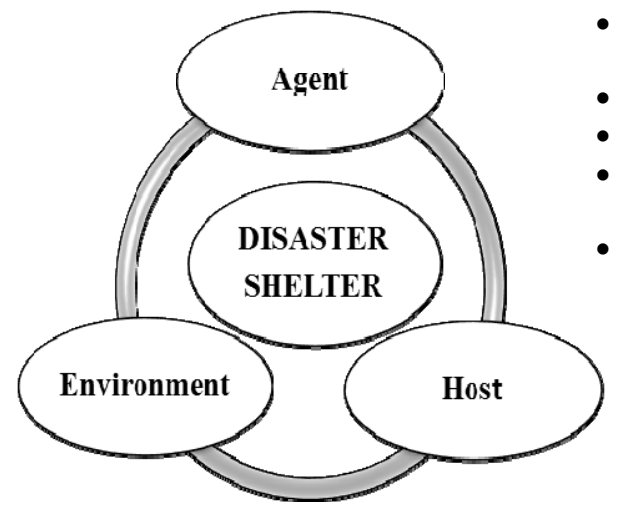

- $\quad$ Chronically or acutely ill individuals

- Very young/older residents

- Pregnant women

- Unvaccinated or susceptible people

- Functional needs or disabilities

- $\quad$ Limited hygiene \& sanitation

- Austere conditions

Figure 1. Theoretical Model of the Public Health Triad Showing the Potential Interaction between the Host, Agent and Environment in a Disaster Shelter Facility

In 2008, the CDC released the new "Environmental Health Assessment Form for Shelters” for rapid assessment of shelters during disasters also known as the CDC shelter tool. ${ }^{16}$ This tool was created following recommendations created during the CDC Hurricane Katrina After Action Review process and developed in collaboration with local/state health departments, ARC and an academic institution. ${ }^{17}$ Since then, the CDC shelter tool and form instructions have been available to users on the CDC website. 
Moreover, over two thousand environmental health personnel from state, local, and territorial environmental health agencies have received training in the use of this tool as part of CDC's Environmental Health Training in Emergency Response (EHTER). ${ }^{18}$

Personal communications with several states, as well as other anecdotal information, suggests that various US states have used the CDC shelter tool, a modified version, or their own jurisdictional tool during recent disasters or emergencies. In addition, in 2012, the CDC Public Health Emergency Preparedness Grant (PHEP) incorporated guidance for the implementation of environmental health assessments by jurisdictions receiving PHEP funds as part of their mass care preparedness activities. ${ }^{19}$

To date, little is known as to how prevalent environmental health shelter assessments during disasters are in state and territorial jurisdictions. There are a number of surveys documenting state and territorial progress in preparedness efforts including public health surveillance, laboratory, and collaborations in many areas including hospitals. ${ }^{20,21}$ However, no surveys have assessed knowledge and preparedness for activities such as conducting environmental health disaster assessments during disasters. Furthermore, is not known how many jurisdictions have knowledge about these methods, assessment tools, or engagement in planning activities with key partners as part of disaster preparedness activities.

In 2013, we conducted a cross-sectional State and Territorial Use of Shelter Assessments Survey known as STUSA to ascertain environmental health departments' knowledge, awareness, familiarity, and other aspects of preparedness (planning, training, exercises, collaborations, and operational procedures) for conducting shelter assessments 
in all 50 US states, the District of Columbia (DC) and commonwealths and territories, including those located in the Caribbean and the Pacific regions: American Samoa, Guam, the Commonwealth of the Northern Mariana Islands, Commonwealth of Puerto Rico, and the US Virgin Islands. Our objectives were several: 1) ascertain the prevalence of environmental health assessments of shelters; 2) establish how knowledgeable these jurisdictions are about these methods and the information collected in these assessments,

and finally; 3) gather information about the jurisdiction roles, preparedness, training, and partners engaged in planning and exercises related to disaster shelters. We report the findings of this survey.

METHODS

We used a cross-sectional survey to measure knowledge, and preparedness aspects related to utilization of environmental health shelter assessments by US states and territories. Participants sampled included environmental health program directors or their designees in the jurisdictions. The survey was carried out between May and August 2013. The STUSA survey tool consisted of 15 primary questions grouped under five main domains: knowledge and familiarity about shelter assessments; procedures and training; utilization of assessment tools; participation in planning and exercises; and respondent survey. Knowledge and familiarity questions were designed to assess a jurisdiction's awareness of shelter assessment tools and familiarity with the concepts and information collected in these assessments. Questions pertaining to procedures and training ascertained whether jurisdictions had developed procedures, conducted formal training on shelter assessments and defined roles and responsibilities for executing these 
assessments during emergencies. Questions related to utilization of assessment tools queried whether the jurisdiction had identified or selected an assessment tool or tools. Finally, questions regarding the domain of participation in planning and exercises were intended to gain a sense of the engagement among partners in disaster shelter preparedness and planning. The STUSA survey tool was initially pilot-tested by officials in two states and one territorial public health jurisdictions. Upon completion of the pilot test, modifications were made to the questionnaire on the basis of recommendations.

Our goal was to receive one survey response from each jurisdiction as completed by state or territorial environmental health program directors or their designees. The list of key contacts at the jurisdiction was prepared using information available from public health organizations, meetings and state and territorial websites. During the spring of 2013, state and territorial environmental health directors received an initial e-mail notification about our interest of conducting a survey. In late spring of 2013, a formal letter of invitation to participate in the survey was sent electronically to environmental health directors. Participants were given the option of answering the STUSA survey themselves or to forward the survey tool to the appropriate department/designee for action. This was done in anticipation of potential shift in jurisdictional responsibilities as a result of federal funding for preparedness and response activities. We anticipated that, in some jurisdictions, a variety of response operations including disaster assessments may have been delegated to other areas of the public health or state environmental health entities. 
Survey participation was voluntary using secure online survey tool developed and made available to the jurisdictions via e-mail after they were contacted by mail or phone. Qualtrics ${ }^{\circledR}$, a survey platform available from FIU, was used for the on-line survey (Qualtrics, Provo, UT). The “STUSA survey package” consisted of a self-administered survey tool, a cover letter, and a letter of support. Participants were provided with three options for completing the survey: on-line at the Qualtrics site, as an attachment via email, or as a hardcopy via US postal service mail. For those respondents choosing to use the on-line questionnaire, a link to the survey site was attached in both the e-mail invitation and in the attached survey tool that was sent by e-mail. All respondents that failed to answer the survey after two weeks were contacted by follow-up e-mail and phone call. After five contact attempts with no response, a jurisdiction was considered as not interested in participating. All surveys received by e-mail and regular mail were checked for duplicates and entered on a separate data entry file. Records were subsequently merged into one file for analysis and interpretation. The FIU Institutional Review Board examined and approved the research.

IBM SPSS Statistics for Windows (Version 21.0) was used to analyze the data (Armonk, NY: IBM Corp.). For analyses, data were stratified by type of jurisdiction and population size. All data was analyzed and reported in an aggregate manner. Descriptive statistics including frequencies and cross tabulations were used for describing the participant characteristics and overall knowledge, familiarity and preparedness for environmental health shelter assessments of disaster shelters. Fischer's exact test was used to examine parameters related to knowledge and familiarity; and adoption of 
operation procedures; preparedness; and collaboration with key partners; all within the context of the type (state vs territorial \& DC) and population size of the jurisdictions. The significance level for the analyses was set at $p<0.05$.

\section{RESULTS}

Fifty-five out of a total of 56 jurisdictions responded to the survey, a response rate of 98\%. This included respondents from 49 US states and all territories, including Caribbean and the Pacific regions, table 1. Knowledge and familiarity reported by jurisdictions of environmental health shelter assessments was very high, table 2 . Approximately $92 \%$ of states and $100 \%$ of territories were found to be knowledgeable on these assessments methods $(p=1.00)$. In the population size group analysis (small, medium, large, and mega), larger jurisdictions were found to be more knowledgeable: $100 \%, 81 \%, 100 \%, 100 \%$ respectively $(p=0.08)$.

Knowledge of environmental health shelter assessments tools available was found to be almost similar in both states and territories, $76 \%$ vs $80 \%$ respectively $(p=1.00)$. In population size, mega size jurisdictions were found to be most knowledgeable about tools with $86 \%$ ( $p=0.92$ ). In terms of familiarity with the information collected by these tools, $88 \%$ of states and $80 \%$ of territories were familiar with the information collected by these assessments $(p=0.52)$. In the population size groups, small and mega size jurisdictions scored the highest, $91 \%$ and $100 \%$ respectively were found to be most familiar with the information contained on those tools $(p=0.60)$.

In the area of preparedness for environmental health shelter assessments, $79 \%$ of states and $83 \%$ of territories indicated they are already using or considering using these 
environmental health shelter assessments methods during future disasters $(p=1.00)$, table 3. However, only $41 \%$ of the states and $60 \%$ of territories reported having formal training in these methods $(p=0.64)$. In population size, medium and large size jurisdictions reported the highest levels of training with 53\% and 43\% respectively and mega size jurisdictions reported the lowest $(p=0.65)$.

Table 1. Number and Percent of Responses by Jurisdiction Type and Population Size, STUSA, 2013

\begin{tabular}{lrr}
\hline Characteristic & $N$ & $(\%)$ \\
\hline Jurisdiction Type & & \\
$\quad$ State* & 49 & 89.1 \\
Territories \& DC & 6 & 10.9 \\
$\quad$ Total & 55 & 100.0 \\
Population Size & & \\
$\quad$ <1 million (Small) & 12 & 21.8 \\
1-5 million (Medium) & 21 & 38.2 \\
5-10 million (Large) & 15 & 27.3 \\
$>$ 10 million (Mega) & 7 & 12.7 \\
Total & 55 & 100.0 \\
\hline
\end{tabular}

*One state did not respond to the survey

With regard to operational procedures $53 \%$ of states and of $50 \%$ territories $(p=$ 1.00) reported having procedures for shelter assessments. Mega size jurisdictions scored the lowest in this area with only $29 \%$ whereas large size jurisdictions scored the highest or 64\% ( $p=0.33)$. Other preparedness activities assessed included planning and disaster exercises. Our results showed that $96 \%$ of states and $83 \%$ of territories $(p=0.31)$ of jurisdictions participates in disaster planning with shelter partners. In addition, $88 \%$ of states and $83 \%$ of territories $(p=0.56)$ reported participating in disaster drills. 
In the population size category most jurisdictions scored reasonable high with regards to planning activities with disaster shelter partners. These findings were consistent across jurisdictions regardless of size. The lowest percentage score was on the large size jurisdictions group with $87 \%(p=0.33)$.

In regard to the participation in disaster drills and exercises with shelter partners, large size jurisdictions scored the lowest with or $80 \%$, medium size jurisdictions scored the highest or $100 \%(p=0.29)$. When asked about specific planning partners most jurisdictions reported collaborations mostly with emergency management (96\%) and ARC (80\%). Similar findings were reported for participation in disaster exercises and drills with shelter partners, figures 2-3. 
Table 2. Number and Percent of Knowledge and Familiarity with Shelter Assessment Responses by Jurisdiction Type and Population Size, STUSA, 2013

\begin{tabular}{|c|c|c|c|c|c|c|c|c|c|c|c|c|c|c|}
\hline \multirow[b]{3}{*}{ Question } & \multicolumn{4}{|c|}{ Jurisdiction Type } & \multicolumn{10}{|c|}{ Population Size (in millions) } \\
\hline & \multicolumn{2}{|c|}{ States } & \multicolumn{2}{|c|}{$\begin{array}{c}\text { Territories, } \\
\text { DC } \\
\end{array}$} & \multicolumn{3}{|c|}{$<1$} & \multicolumn{2}{|c|}{$1-4.9$} & \multicolumn{2}{|c|}{$5-10$} & \multicolumn{3}{|c|}{$>10$} \\
\hline & $N$ & $\%$ & $N$ & $\%$ & & $N$ & $\%$ & $N$ & $\%$ & $N$ & $\%$ & $N$ & $\%$ & \\
\hline \multicolumn{15}{|c|}{ Knowledge about environmental health shelter assessments } \\
\hline Yes & 45 & 91.8 & 5 & 100.0 & * & 11 & 100.0 & 17 & 81.0 & 15 & 100.0 & 7 & 100.0 & $*$ \\
\hline No & 4 & 8.2 & 0 & 0 & & 0 & 0 & 4 & 19.0 & 0 & 0 & 0 & 0 & \\
\hline Yes & 34 & 75.6 & 4 & 80.0 & $*$ & 8 & 72.7 & 14 & 73.7 & 10 & 77.0 & 6 & 85.7 & * \\
\hline No & 11 & 24.4 & 1 & 20.0 & & 3 & 27.3 & 5 & 26.3 & 3 & 23.0 & 1 & 14.3 & \\
\hline \multicolumn{15}{|c|}{ Familiar with the information collected in the environmental health shelter assessments } \\
\hline Yes & 42 & 87.5 & 4 & 80.0 & $*$ & 10 & 90.9 & 17 & 81.0 & 12 & 85.7 & 7 & 100.0 & * \\
\hline No & 6 & 12.2 & 1 & 20.0 & & 1 & 9.1 & 4 & 19.0 & 2 & 14.3 & 0 & 0 & \\
\hline
\end{tabular}

Only Yes \& No answers are included 
Table 3. Number and Percent of Responses about Preparedness Measures for Shelter Assessments by Jurisdiction Type and Population Size, STUSA, 2013

\begin{tabular}{|c|c|c|c|c|c|c|c|c|c|c|c|c|c|c|}
\hline \multirow[b]{3}{*}{ Question } & \multicolumn{4}{|c|}{ Jurisdiction Type } & & \multicolumn{8}{|c|}{ Population Size (in millions) } & \\
\hline & \multicolumn{2}{|c|}{ States } & \multicolumn{2}{|c|}{$\begin{array}{c}\text { Territories, } \\
\text { DC }\end{array}$} & & \multicolumn{2}{|c|}{$<1$} & \multicolumn{2}{|c|}{$1-4.9$} & \multicolumn{2}{|c|}{$5-10$} & \multicolumn{2}{|c|}{$>10$} & \\
\hline & $N$ & $\%$ & $N$ & $\%$ & & $N$ & $\%$ & $N$ & $\%$ & $N$ & $\%$ & $N$ & $\%$ & \\
\hline \multicolumn{14}{|c|}{ Environmental health shelter assessments are considered or already conducted in disasters } & \\
\hline Yes & 37 & 78.7 & 5 & 83.3 & $*$ & 9 & 75.0 & 14 & 73.7 & 14 & 93.3 & 5 & 71.4 & $*$ \\
\hline No & 10 & 20.4 & 1 & 16.7 & & 3 & 25.0 & 5 & 26.3 & 1 & 6.7 & 2 & 28.6 & \\
\hline \multicolumn{15}{|c|}{ Formal training in shelter assessments } \\
\hline Yes & 17 & 40.5 & 3 & 60.0 & $*$ & 3 & 33.3 & 9 & 52.9 & 6 & 42.9 & 2 & 28.6 & * \\
\hline No & 25 & 59.5 & 2 & 40.0 & & 6 & 66.7 & 8 & 47.1 & 8 & 57.1 & 5 & 71.4 & \\
\hline \multicolumn{15}{|c|}{ Have operational procedures for assessments } \\
\hline Yes & 25 & 53.2 & 3 & 50.0 & $*$ & 5 & 41.7 & 12 & 60.0 & 9 & 64.3 & 2 & 28.6 & * \\
\hline No & 22 & 46.8 & 3 & 50.0 & & 7 & 58.3 & 8 & 40.0 & 5 & 35.7 & 5 & 71.4 & \\
\hline \multicolumn{15}{|c|}{ Engages in disaster planning with shelter partners } \\
\hline Yes & 44 & 95.7 & 5 & 83.3 & $*$ & 10 & 90.9 & 19 & 100.0 & 13 & 86.7 & 7 & 100 & * \\
\hline No & 2 & 4.3 & 1 & 16.7 & & 1 & 9.1 & 0 & 0.0 & 2 & 13.3 & 0 & 0 & \\
\hline \multicolumn{15}{|c|}{ Participates in disaster drill \& exercise with shelter partners } \\
\hline Yes & 38 & 88.4 & 5 & 83.3 & $*$ & 9 & 81.8 & 17 & 100.0 & 12 & 80.0 & 5 & 83.3 & $*$ \\
\hline No & 5 & 11.6 & 1 & 16.7 & & 2 & 18.2 & 0 & 0.0 & 3 & 20.0 & 1 & 16.7 & \\
\hline
\end{tabular}

Only Yes \& No answers are included
Ond $>0.05, * * \mathrm{p}<0.05$ 


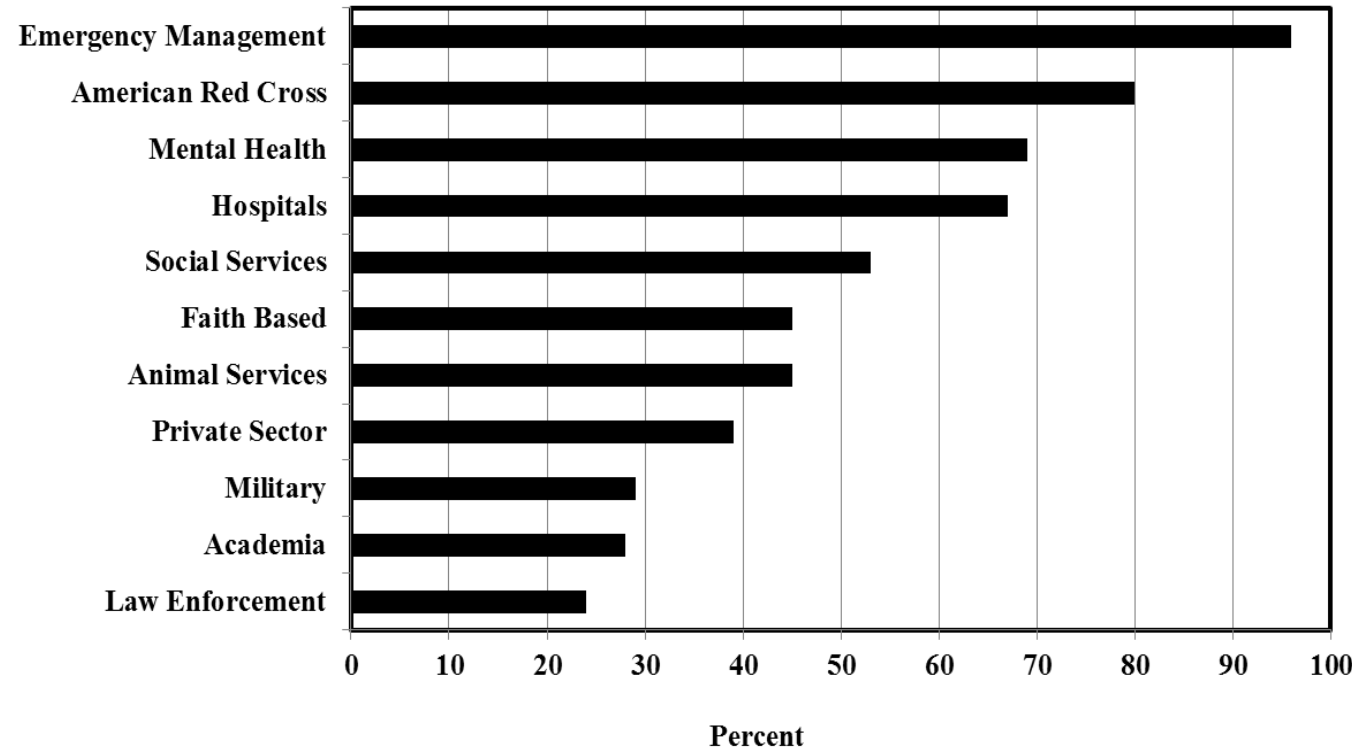

Figure 2. Selected Mass Care Disaster Planning Partners, by Percentage, Reported by Survey Respondents, STUSA, 2013

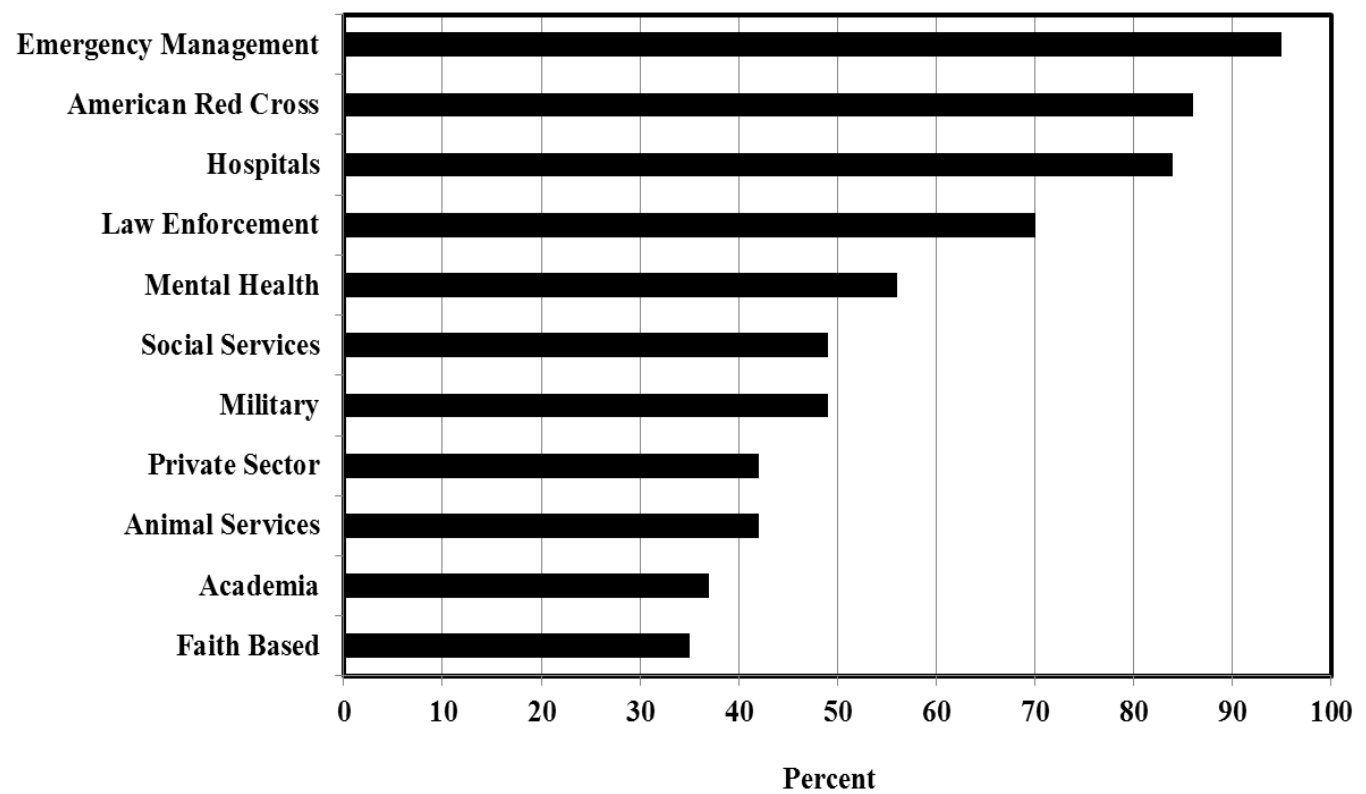

Figure 3. Selected Mass Care Disaster Drill/Exercise Partners, by Percentage, Reported by Survey Respondents, STUSA, 2013 


\section{DISCUSSION}

Our results reveal that, although the states and jurisdictions have a high level of knowledge and familiarity with environmental health shelter assessment methods, improvement could be made in the way jurisdictions train for and operationalized these procedures during actual disasters. For example, our results showed that low levels of training and low prevalence of having operational procedures for shelter assessments mostly among large size jurisdictions. This is despite current efforts by lead agencies in mass care such as FEMA and ARC to increase the safety and shelter service accommodations for persons with functional needs. ${ }^{22,23}$ Perhaps fiscal and staffing constraints that many public health agencies face today, such as budget and staffing cuts, re-structuring in services, and frequent staff turnover may have impacted ways jurisdictions incorporate these disaster assessments activities into disaster plans and procedures. $^{23,24}$ Unfortunately, these gaps could not be explained and warrant further investigation as to why these preparedness areas or levels are not higher.

This survey has some limitations. As of today, no actual or clear national shelter standards exist defining these environmental health assessment methods for shelter facilities, particularly in domestic settings during disasters. As a result, survey respondents might have misinterpreted terminology used in the survey. This is in contrast to events such as complex emergencies in international settings that use agreeable standards created by Sphere Project or the Water Sanitation and Hygiene cluster from United Nations Children's Fund. ${ }^{25,26}$ Other factors such as how prone a jurisdiction maybe to disasters may also contribute to creating interest in having such a resource for 
disasters. Many jurisdictions may not perceive such urgency or risk and as a result they do not see value in spending resources in such efforts.

In addition, our survey was completely anonymous and did not allow us to assess the respondent's level of experience or knowledge in environmental health shelter assessment operations of the respondents. However, we are confident that the multiple interactions and feedback between the survey team and the respondents assure us of the jurisdictions' best efforts to participate in this survey and to ensure that the survey questions were answered by knowledgeable staff. Another concern was the possibility that some respondents were not familiar with specific jargon, terms like "disaster shelter assessments" or "mass care" used in the survey. However, since 2012 the CDC Public Health Emergency Preparedness grant has supported efforts in the area of mass-care partners, particularly in working with shelter partners. These funding requirements included specific actions and mass-care activities that grantees were expected to engage in at their jurisdictional level.

Our survey shows encouraging signs. For example, most public health agencies appear to be engaged in disaster planning and are participating in disaster drills with key shelter partners. Furthermore, many of the jurisdictions disclosed that they will be considering using these assessments in future disasters. The public health sector has the lead for disease and injury prevention efforts in disasters and, as such, has the operational and analytical knowledge to carry out these assessments. Information from these assessments could eventually be used by agencies involve in mass care activities: lessons learned, training of assessors and shelter managers, strengthening mass care standards 
and development of operational procedures for carrying out disaster assessments in shelter facilities. In addition, information about shelter deficiencies available may be useful to describe living conditions in different disaster shelter settings (e.g. megashelters) and public facilities (e.g. convention centers vs schools); and for evaluating effectiveness in reducing associated morbidity and mortality across disaster types.

\section{CONCLUSION}

Environmental health shelter assessments are disaster-related activities that are necessary to ensure the well-being of those living in disaster shelters. Our findings suggest that environmental health shelter assessments activities are to some extent considered in these US state and territorial jurisdictions. The public health sector, through its environmental health component and with support from disaster partners, may want to consider incorporating these assessments as part of disaster response plans and procedures. These environmental health shelter assessment data collected during disasters may also provide insights and knowledge for new and targeted protective actions that may help to protect people during future disasters events. 


\section{REFERENCES}

1. EM-DAT: The OFDA/CRED International Disaster Database. Université Catholique de Louvain - Brussels - Belgium. Retrieved from: http://www.emdat.be/. Accessed March2014

2. Noji E. The Public Health Consequences of Disasters. Oxford Press. New York 1997.

3. Malilay J. Public health assessments in disaster settings: recommendations for a multidisciplinary approach. Prehospital and Disaster Medicine 2005;15:167-172.

4. Centers for Disease Control and Prevention (CDC). Tropical storm Allison rapid needs assessment—Houston, Texas, June 2001. MMWR 2002;51:365-369.

5. Greenough PG, Kirsh TD. Public health response-assessing needs. New England Journal of Medicine 2005;353:1544-1546.

6. CDC. Rapid needs assessment of two rural communities after hurricane WilmaHendry County, Florida, November 1-2, 2005. MMWR 2006;55:429-431.

7. CDC. Hurricane Ike rapid needs assessment---Houston, Texas, September 2008. MMWR 2009;58:1066-1071.

8. Choudhary E, Chen TH, Martin C, Vagi S, Roth J, Keim M, Noe R, Ponausuaia SE, Lemusu S, Bayleyegn T, Wolkin A. Public health needs assessments of Tutuila Island, American Samoa, after the 2009 tsunami. Disaster Med Public Health Preparedness 2012;6:209-216.

9. Hlady WG, Quenemoen LE, Armenia-Cope RR, Hurt KJ, Malilay J, Noji EK, Wurm G. Use of a modified cluster sampling method to perform rapid needs assessment after a hurricane Andrew. Annals of Emergency Medicine 1994;23:719-725.

10. Deitchman S. What have we learned? Needs assessment. Prehospital and Disaster Medicine 2005;20:468-470.

11. Humanitarian charter and minimum standards in disaster response 2011 edition. Sphere Project. Retrieved from: http://www.sphereproject.org/handbook/. Accessed March 2013.

12. Infection prevention and control in disaster shelters. Association for Professionals in Infection Control and Epidemiology. Retrieved from: http://www.apic.org/Resource_/TinyMceFileManager/Practice_Guidance/Emergency _Preparedness/Shelters_Disasters.pdf. Accessed September 2013. 
13. Guidance on planning for integration of functional needs support services in general population shelters. November 2010. Federal Emergency Management Agency (FEMA) website. http://www.fema.gov/pdf/about/odic/fnss_guidance.pdf. Accessed April 14, 2014.

14. Voluntary organizations in disasters. FEMA should more fully assess organizations mass care capabilities and update the Red Cross role in catastrophic events. September 18, 2008. Government Accountability Office. Retrieved from: http://www.gao.gov/products/GAO-08-823. Accessed October 2013.

15. National Response Framework. FEMA. Retrieved from: https://s3-us-gov-west1.amazonaws.com/dam-production/uploads/20130726-1914-250451246/final_national_response_framework_20130501.pdf. Accessed July 2014.

16. Preparedness and Response for Public Health disasters. Disaster Epidemiology. Retrieved from: http://www.cdc.gov/nceh/hsb/disaster/epidemiology.htm. Accessed April 2012.

17. Cruz MA, Miller M, Kapil N, Kalis M. Assessing Environmental health issues in shelters during disaster operations. Retrieved from: http://www.integratedtrainingsummit.org/presentations/2009/main_training_summit/3 9_environmental_health_assessments_and_tools_utilized_in_disaster_response_eve nts_-_cruz.pdf. Accessed November 2013.

18. Environmental Health Training in Emergency Response (EHTER). Retrieved from: http://www.cdc.gov/nceh/ehs/eLearn/EHTER.htm. Accessed November 2013.

19. RFA-TP12-1201 Hospital Preparedness Program (HPP) and Public Health Emergency Preparedness (PHEP) Cooperative Agreements. Retrieved from: http://www.cdc.gov/phpr/coopagreement.htm. Accessed December 2012.

20. The 2013-2014 National snapshot of public health preparedness. Retrieved from: http://www.cdc.gov/phpr/pubs/2013. Accessed October 2014.

21. Beitsch L, Kodolikar S, Stephens T, Shodell D, Clawson A, Menachemi N, Brooks R. A state-based analysis of public health preparedness programs in the United States. Public Health Reports 2006;121:737-745.

22. National Mass Care Strategy. Retrieved from: http://nationalmasscarestrategy.files.wordpress.com/2012/10/national-mass-carestrategy-september-2012-final4.pdf. Accessed February 2014.

23. Budget cuts continue to affect the health of Americans. Association of State and Territorial Health Officials. Retrieved from: http://www.astho.org/Public- 
Policy/2013-Advocacy-Materials/2013-Hill-Day-Budget-Cuts-Brief/2013/. Accessed January 2014.

24. Press Release: Presidents budget falls short on funding public health programs strengthen others. Cuts to public health jeopardize our nation's economic health and competitive edge. American Public Health Association. Retrieved from: http://www.apha.org/about/news/pressreleases/2013/Presidentsbudgetfallsshort.htm. Accessed February 2014.

25. Sphere Project. Retrieved from: http://www.sphereproject.org/about/. Accessed April 2014.

26. Water Sanitation and Hygiene (WASH). Retrieved from: http://washcluster.net/about-us/. Accessed April 2014 


\title{
CHAPTER IV
}

\author{
EVALUATION OF RISKS FOR HURRICANES AND EARTHQUAKES AS \\ PREDICTORS OF JURISDICTIONAL KNOWLEDGE AND PREPAREDNESS FOR \\ ENVIRONMENTAL HEALTH SHELTER ASSESSMENTS
}

\begin{abstract}
Background: During disasters, public health assessments are often carried out in order to obtain information about the affected populations. In order for jurisdictions to accomplish such tasks the need to have the basics: knowledge, training and procedures in these methods. Having the inherent disaster risk or threat of a major disaster such as hurricanes or earthquakes may serve as motivators for better disaster readiness. During this research we attempted to ascertain whether jurisdictional knowledge and preparedness was influenced by potential risks for hurricanes and earthquake. We analyzed data available from the 2013 State and Territorial Use of Shelter Assessments (STUSA) survey to: 1) describe knowledge and in jurisdictions with known risks for earthquakes and hurricanes; 2) examine whether these risks predicted better knowledge and preparedness in those jurisdictions.
\end{abstract}

Methods: Descriptive statistics were used to describe the sample. Univariate and multivariate statistics were used to compare groups. Two logistic regression models were used to explore relationships between dependent variables (knowledge and preparedness) to the independent variables (type \& size of jurisdictions, risk of earthquakes and hurricanes). 
Results: In the multivariate analysis, jurisdictions with both risks were found to be more slightly more knowledgeable in most areas about knowledge of shelter assessments compared to those with no risks. In the preparedness area, jurisdictions with both risks reported having more experience using assessments and participating in planning activities with shelter partners than those in the no risk group. The results of our logistic regression models did not revealed significant differences in knowledge or preparedness in the use these assessments regardless of risks, even after adjusting for population type and size.

Conclusion: This is the first attempt to use disaster risk as a measure to predict knowledge and preparedness in areas at higher risk for certain disasters. Our research do not concluded such risks were good predictors of knowledge or preparedness. Perhaps, other potential measures of risks or hazards should be evaluated as better predictor's than just earthquake and hurricane risks. These may include previous numbers of disasters and emergencies, resource or budgetary constraints, potential regional or geographic risks not assessed or used in the analysis.

Discussion: Public health disaster assessment methods could provide useful data about the status of the populations affected in high risk jurisdictions. As such, better understanding of these factors may increase our ability to work, particularly with those jurisdictions lacking knowledge and preparedness, to increase capacity to perform these disaster assessment methods. 


\section{INTRODUCTION}

The term “disaster” implies that a complex situation may have occurred with a likelihood of affecting severely a population. The causative agent maybe natural, technological, or even terrorism related. All-hazards planning are an important aspect of public health preparedness for high-consequence natural hazards. ${ }^{1}$ The US Department of Homeland Security defines preparedness as “a continuous cycle of planning, organizing, training, equipping, drills and exercises, evaluating and taking corrective actions in an effort to ensure effective coordination during incident response.” 2

One important aspect of preparedness is the need for having systems or methods for gathering information for decision making and for protecting populations at risk. ${ }^{3}$ Large disasters, like hurricanes, and earthquakes, can affect communities in many areas of the US and territories and cause significant damage to key infrastructure, services, and communities. There are several areas at risk for these events in the US. These jurisdictions at risk includes the contiguous states, Alaska, Hawaii all the US Caribbean and Pacific territories according to scientific and event information available from agencies like the National Oceanic and Atmospheric Administration (NOAA) and US Geological Survey (USGS). Figures 1 \& 2, depict these hurricane and earthquake prone jurisdictions.

Hurricane effects such as wind, storm surge and flooding, pose significant risks to communities in coastal areas. Many also believe that climate change may affect the frequency and strength of future hurricanes. ${ }^{5,6,7}$ This could be an area of concern for emergency planners. In 2010, NOAA conducted a demographic shift analysis of this 
trend. Results revealed that today approximately 52\% of the country's population lives within 50 miles of coastal areas. Public health preparedness in these jurisdictions must include public health planning activities for supporting large numbers of shelter facilities. ${ }^{8}$ A precedent for this was established in 2005 hurricane season when at the peak of the unusually busy Gulf hurricane season emergency response more than 1300 shelters were reported in operation in 27 states. ${ }^{9,10}$

Earthquakes are events that can occur suddenly when the edges of moving plates around the earth suddenly release energy resulting in ground motion. According to the USGS, the lead US agency for monitoring seismic activity, approximately 166 million US residents in 37 states live in areas at higher risk of earthquakes. These numbers have been revised up from a previous estimate that placed 75 million at risk in 39 states. Other US areas at risk include all Pacific and Caribbean territories. ${ }^{11}$ Earthquakes of small magnitude occur almost daily in many of these US regions. However, earthquakes of catastrophic magnitude are always a possibility and several have affected areas of the US in the past. The USGS estimates that the occurrence of our next catastrophic earthquake is only a matter of time. ${ }^{12,13,14}$ This risk maybe accentuated by the fact that earthquakes, in contrast to hurricanes, can strike with little or no warning and many individuals will be caught unprepared. ${ }^{15,16}$ The potential regional or national public health effects of such devastating events require standard approaches for assessing the health status and needs for protecting affected populations. 


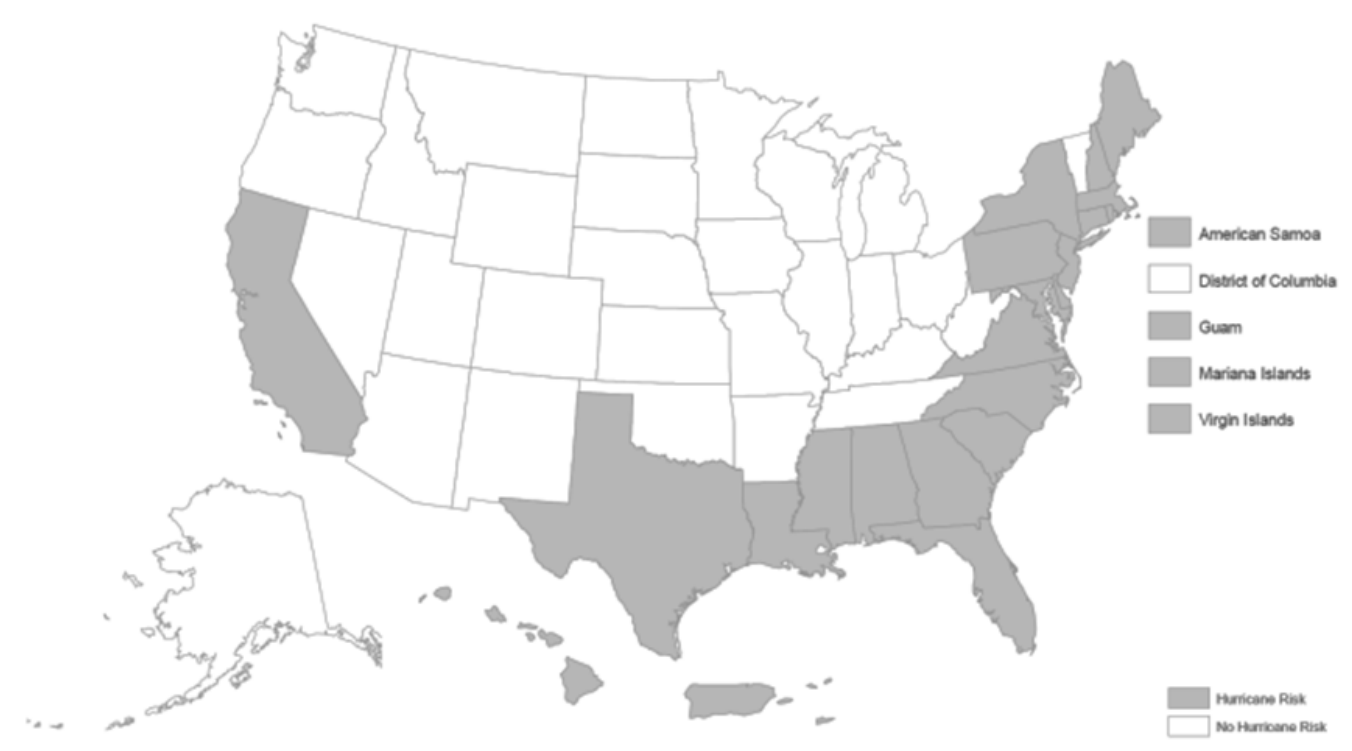

Figure courtesy of CDC Geospatial Research, Analysis and Services Program

Figure 1. Map of US States and Territories Located in Hurricane Prone Areas

One direct effect of these disasters is mass population displacements and creation of vast degrees of homelessness, including entire communities. This often occurs as a result of mandatory evacuations or because large numbers of people are suddenly left homeless due to damage to their homes, creating a demand for disaster shelters. Shelters protect individuals from the direct effects of the disaster and help maintain a sense of community. ${ }^{17}$ When large disasters or emergencies occur and exceed local or state resources, jurisdictions often ask for assistance via the issuance of a Federal Major Disaster or Emergency declaration to support response activities. The activity that involves sheltering is part of what is known in emergency disaster circles as "mass care". 
Mass care includes other humanitarian activities such as feeding, basic medical services, emergency supplies, and family reunification. ${ }^{18,19}$

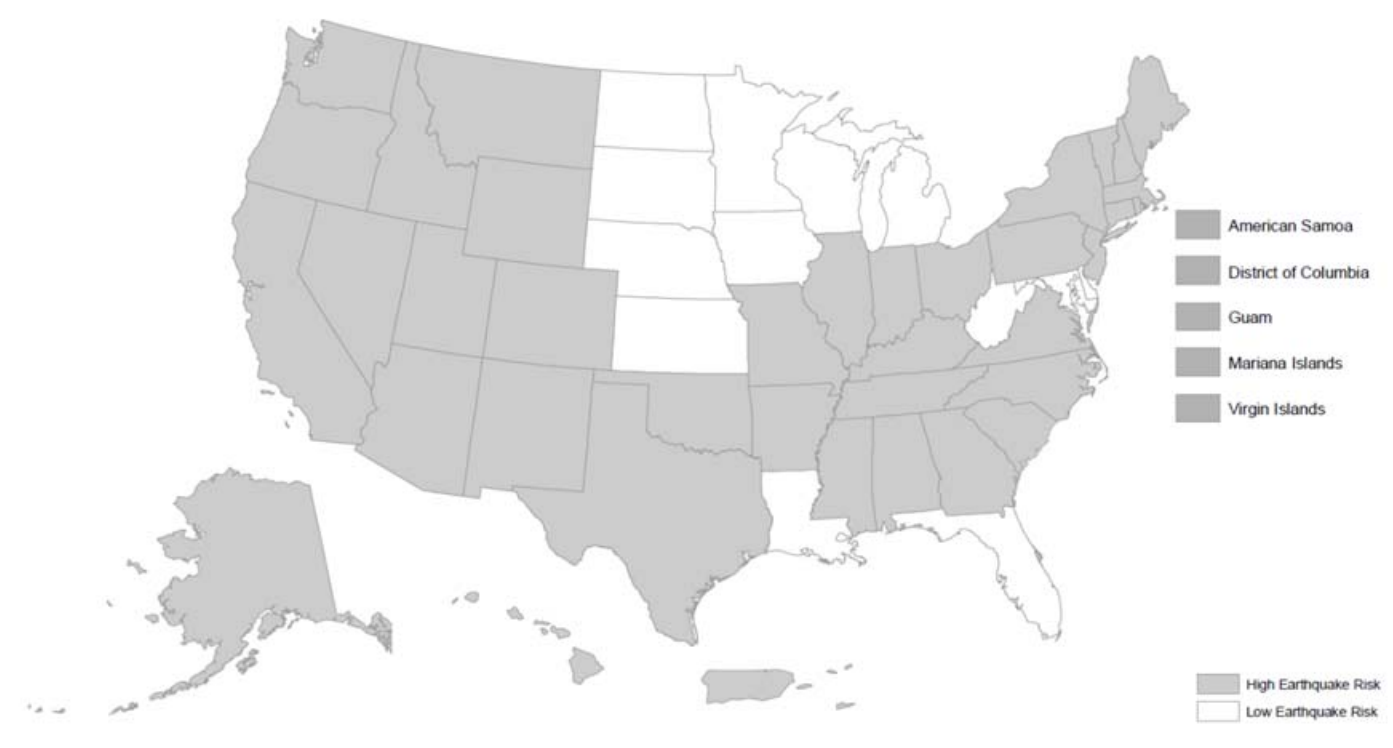

Figure courtesy of CDC Geospatial Research, Analysis and Services Program

Figure 2. Map of US States and Territories Located in Earthquake Prone Areas

During disasters, public health agencies are often not in charge of running shelter operations. Instead they support lead agencies like FEMA, ARC, and volunteer organizations by focusing on public health prevention activities like environmental health, safety and health surveillance. After Hurricanes Katrina and Rita in 2005, concerns were raised by the US Government regarding the ability of mass-care agencies (e.g. FEMA, ARC and other national volunteer organizations) to house or shelter large numbers of affected individuals in catastrophic-level disasters. For example, at the peak 
of the Gulf Coast hurricanes response more than 1300 disaster shelters were in operation in 27 states. In 2012, Hurricane Sandy again demonstrated that gaps still exist in preparedness regarding the way in which we respond and address survivor's needs for safer and healthier environments in disaster shelter facilities. ${ }^{20}$

Disaster shelters have a negative side, as congregate settings they bring people often together under very austere conditions where hygiene, sanitation services, and preventive services may be limited or unavailable. Shelter occupants which include both disaster victims and workers may be socio-economic vulnerable and with mental health, chronic and acute health issues and functional needs (physical, sensory, cognitive or intellectual disabilities). All these have been well documented during previous disasters. ${ }^{21,22,23,24,25,26}$ One potential and useful approach to monitoring shelter facilities in times of disasters is to rapidly assess the living environment of occupants. ${ }^{27}$ For that, public health agencies have at their disposal a number of disaster risk assessment tools, among them, environmental health assessments. $28,29,30,31,32$

In particular, these assessments focus on evaluating living conditions; hygiene and sanitation, safety, and security in facilities. ${ }^{33}$ There are a number of shelter assessment tools available from agencies like the CDC and individual states which are available for rapid deployment. There is also a need to have public health personal trained in their use. The CDC and some state jurisdictions have addressed this gap by developing training in this area for public health officials and, according to the CDC, more than 2500 public health professional from domestic and international organizations have been trained in these disaster assessments methods. ${ }^{34,35}$ 
During recent years after, (mostly after the 9/11 terrorist attacks), several surveys have been carried-out to evaluate overall state and local public health preparedness programs ${ }^{37}$ However, none have undertaken the task of evaluating specific knowledge and preparedness aspects of emergency response activities like environmental health assessments by environmental health agencies in jurisdictions that have particular risks or hazards. In 2013, a cross-sectional survey known as the State and Territorial Use of Shelter Assessments or "STUSA" was conducted to ascertain the prevalence, knowledge, and preparedness of environmental health shelter assessments in those jurisdictions. Information about the overall survey design, data collections, analysis, and results has been discussed elsewhere. ${ }^{38}$

In 2014, an additional analysis of STUSA survey data was conducted to: 1) describe knowledge and preparedness in jurisdictions with specific disaster risks (hurricanes or earthquakes); 2) determine whether jurisdictions with those risks demonstrated better knowledge and preparedness compared to lesser or not known risks. We will test our assumption that because of such risks, those jurisdictions (regardless or type and size) will show to be more knowledgeable of and prepared for performance of disaster shelter assessments as compared to jurisdictions with lesser risks. This report describes our findings.

\section{METHODS}

In the spring of 2013 self-reported responses were collected from environmental health or environmental health program directors or their designees in the 50 US states, the District of Columbia and 5 US territories in what was known as the State and 
Territorial Utilization of Shelter Assessment survey or STUSA. The secure online survey instrument was distributed electronically to state and territorial environmental health directors of their designees. The tool included 15 primary questions grouped under five main areas or domains: knowledge and familiarity with shelter concepts, tools, methods; procedures and training questions; utilization of assessment tools; participation in planning and exercises with shelter partners; and respondent feedback. Jurisdictions completed the survey via any methods that was most convenient to them: on-line survey, via email, or U.S. postal service. A 98\% response rate was achieved. Data was analyzed and reported in an aggregate manner. The FIU Institutional Review Board (IRB) approved the original STUSA research proposal as an exempt protocol.

Information about earthquake and hurricane risk areas in US states and territories was obtained by contacting the USGS and by reviewing NOAA information available on their public websites. In addition, population variables were constructed for state and territorial population using data from the 2010 U.S Census available in their open access website. US maps depicting high risk areas were provide with the CDC Geospatial Research, Analysis and Services Program (GRASP). In addition, IBM SPSS Statistics for Windows (Version 21.0) was used to analyze the data (Armonk, NY: IBM Corp). Descriptive statistics, frequencies and cross tabulation were used for the analysis of this study. Finally, univariate and multivariate analyses were conducted to predict the knowledge and preparedness.

The significance of knowledge and preparedness activities was assessed using logistic regression and our level of significance was established at $\mathrm{p}<0.05$. Knowledge 
and preparedness for conducting assessments (dependent variables) was explored using a logistic regression model that included population size, type of jurisdiction and risks (independent variables). Each jurisdiction was only assigned one of four risk groups for this analysis, either hurricane, but not earthquake; earthquake, but not hurricane; both, or neither. To be considered knowledgeable jurisdictions needed at least four "yes” responses for the five questions about knowledge. Similarly, jurisdictions needed to answer "yes" to at least three out of four questions to be deemed prepared. For both models we selected covariates that may have effects on a jurisdiction's ability to engage in these activities, in this instance exposure to known risks and characteristics such as type of jurisdiction and size of the population.

\section{RESULTS}

Overall responses were available from 49 US states and 6 territories from the original STUSA that was carried out in 2013. For this manuscript purposes, results of the analysis are presented in three sub-sections depicted in tables 1-6 that correspond to the following areas of the survey: jurisdictional demographical and risk characteristics of survey respondents, jurisdictional knowledge and preparedness about environmental health shelter assessments.

Population in these jurisdictions ranged from small jurisdictions (22\%), medium (38\%), large (27\%) and mega size (13\%), table 1. Of those jurisdictions that responded, 4 (7\%) were deemed to be jurisdictions at risk only for hurricanes, 21 (38\%) at risk only for earthquakes, 21(38\%) of these jurisdictions were considered to be at risk for both 
earthquakes and hurricanes, and 9 (16\%) jurisdictions were deemed to have very low or no risk of hurricanes or earthquakes, table 2.

Table 1. Demographic Characteristics of State and Territorial Jurisdictions Respondents by Number and Percent, STUSA, 2013

\begin{tabular}{lrc}
\hline Characteristic & $N$ & $\%$ \\
\hline Island & 6 & 10.9 \\
Non-Island & 49 & 89.1 \\
$\quad$ Total & 55 & 100.0 \\
Population Size & & \\
$\quad$ 1 million (Small) & 12 & 21.8 \\
1-5 million (Medium) & 21 & 38.2 \\
$5-10$ million (Large) & 15 & 27.3 \\
$>10$ million (Mega) & 7 & 12.7 \\
Total & 55 & 100.0 \\
\hline
\end{tabular}

In the knowledge question category, jurisdictions with no risk, and earthquake risks were less likely to self-report being knowledgeable, than those jurisdiction groups with hurricane and both risks (hurricane and earthquake), table 3. In addition, jurisdictions with both risks were more likely to report being knowledgeable about assessment tools available (76\%) than all the other population risk groups. With regards to familiarity with the types of information collected by the shelter assessment forms hurricane risk jurisdictions scored the highest (86\%). Jurisdictions with both risks also scored the highest with regard to having already selected a shelter assessment tool for conducting these assessments during disasters (67\%). With regards to training, hurricane risk jurisdictions again reported the highest percentage of receiving formal training in shelter assessments (50\%), however these results were found to be low across all jurisdictions regardless of risks. 
With regards to preparedness questions for conducting environmental health assessments of disaster shelters, jurisdictions that have no risks were more likely to report having shelter assessment operational procedures for conducting these assessments in contrast to those in the both risk group (56\% versus 52\%), table 4 . Jurisdictions that have both risks were more likely also than those with no risks to report having experience with conducting these assessments during disasters (81\% versus 78\%). With regards to participation in disaster planning and in disaster drills and exercises, hurricane risk jurisdictions were more likely to report greater involvement in planning (100\%) and drills/exercises (100\%) with shelter partners. The lowest score for both activities was reported by earthquake risk jurisdictions (86\% and 71\% respectively).

We conducted two logistics regression models to test the hypothesis that knowledge and preparedness would be influenced by the jurisdictional risk for earthquakes and hurricanes, population size, and whether or not it is an island (Tables 5 and 6). Results showed that neither model demonstrated any statistically significant association. Since the $95 \mathrm{CI}(0.06-7.88)$ includes 1.0 , the decreased odd (OR=0.69) of knowledge for hurricane risk only groups does not reach statistical significance. This is indicated in table 5.

For the group with both disaster risks the adjusted OR was greater than one (OR $1.44,0.24-8.63)$, though still not found to be statically significant $(p=0.68)$. On the population size groups the adjusted OR's for both medium (OR 1.11, CI 0.23 - 5.24) and mega size (OR 1.63, CI 0.18-15.01) jurisdictions were found to be greater than one however those results were not found to be statistically significant. Also on the 
knowledge model the island group unadjusted OR was significant however that difference disappeared on the adjusted OR, (OR 1.50, CI 0.25- 8.98 versus OR 0.95, CI $0.10-9.32)$.

In the preparedness model, the unadjusted (OR 1.00, CI 0.06-15.99) and the adjusted odd ratios (OR 1.91, CI 0.06-20.69) were found to be significant in hurricane risk only jurisdictions, however not found to be statistically significant, table 6 . In the population size and jurisdiction type groups, the unadjusted and adjusted OR's again were found to be significantly higher in all 3 population groups (medium, large, and mega) however the CI were too wide and these differences were not found to be statistically significant.

Table 2. Risk Characteristics of State and Territorial Jurisdictions Respondents by Number and Percent, STUSA, 2013

\begin{tabular}{lrl}
\hline Characteristic & $N$ & $(\%$ \\
\hline Hurricane risk only & 4 & 7.3 \\
Earthquake risk only & 21 & 38.2 \\
Both risks & 21 & 38.2 \\
No risks & 9 & 16.4 \\
Total & 55 & 100.0 \\
\hline
\end{tabular}


Table 3. Number and Percent of Characteristics of Shelter Assessment Knowledge Responses According to Jurisdictional Risks, STUSA, 2013

\begin{tabular}{|c|c|c|c|c|c|c|c|c|}
\hline \multirow{2}{*}{ Characteristic } & \multicolumn{2}{|c|}{ None } & \multicolumn{2}{|c|}{ Earthquake } & \multicolumn{2}{|c|}{ Hurricane } & \multicolumn{2}{|c|}{ Both } \\
\hline & $N$ & $\%$ & $N$ & $\%$ & $N$ & $\%$ & $N$ & $\%$ \\
\hline Knowledge about concepts & 7 & 77.8 & 19 & 90.5 & 4 & 100 & 20 & 95.2 \\
\hline Knowledge about tools available & 6 & 66.7 & 14 & 66.7 & 2 & 50 & 16 & 76.2 \\
\hline Familiar with type of information collected & 7 & 77.8 & 17 & 81 & 4 & 100 & 18 & 85.7 \\
\hline Has selected a shelter assessment tool & 5 & 55.6 & 11 & 52.4 & 2 & 50 & 14 & 66.7 \\
\hline Has received training & 3 & 33.3 & 6 & 28.3 & 2 & 50 & 9 & 42.9 \\
\hline
\end{tabular}

Table 4. Number and Percent of Characteristics of Shelter Assessment Preparedness Responses According to Jurisdictional Risks, STUSA, 2013

\begin{tabular}{|c|c|c|c|c|c|c|c|c|}
\hline \multirow{2}{*}{ Characteristic } & \multicolumn{2}{|c|}{ None } & \multicolumn{2}{|c|}{ Earthquake } & \multicolumn{2}{|c|}{ Hurricane } & \multicolumn{2}{|c|}{ Both } \\
\hline & $N$ & $\%$ & $N$ & $\%$ & $N$ & $\%$ & $N$ & $\%$ \\
\hline Has operational procedures & 5 & 55.6 & 10 & 47.6 & 2 & 50.0 & 11 & 52.4 \\
\hline Conducts assessment in disaster operations & 7 & 77.8 & 15 & 71.4 & 3 & 75.0 & 17 & 81.0 \\
\hline Participates in disaster planning & 8 & 88.9 & 18 & 85.7 & 4 & 100.0 & 19 & 90.5 \\
\hline Participates in disaster exercise/ drills & 8 & 88.9 & 15 & 71.4 & 4 & 100.0 & 16 & 76.2 \\
\hline
\end{tabular}


Table 5. Knowledge Model Odds Ratios and Confidence Intervals, STUSA, 2013

\begin{tabular}{|c|c|c|c|c|}
\hline Variable & $\begin{array}{c}\text { Unadjusted } \\
\text { OR }\end{array}$ & $95 \% C I$ & $\begin{array}{c}\text { Adjusted } \\
\text { OR }\end{array}$ & $95 \%$ CI \\
\hline \multicolumn{5}{|l|}{ Risks (compared to no risk) } \\
\hline Hurricane & $0.80 *$ & $0.08-8.47$ & $0.69 *$ & $0.06-7.88$ \\
\hline Earthquake & $0.88 *$ & $0.18-4.23$ & $0.82 *$ & $0.17-4.06$ \\
\hline Both (hurricane and earthquake) & $1.60 *$ & $0.32-7.90$ & $1.44 *$ & $0.241-8.63$ \\
\hline \multicolumn{5}{|l|}{ Population size (compared to small) } \\
\hline Medium & $1.16^{*}$ & $0.27-4.93$ & $1.11 *$ & $0.23-5.24$ \\
\hline Large & $0.63 *$ & $0.14-2.89$ & $0.60 *$ & $0.11-3.34$ \\
\hline Mega & $1.79 *$ & $0.24-13.22$ & $1.63 *$ & $0.18-15.01$ \\
\hline \multicolumn{5}{|c|}{ Jurisdiction Type (compared to non-island) } \\
\hline Island & $1.50 *$ & $0.25-8.98$ & $0.94 *$ & $0.10-9.32$ \\
\hline
\end{tabular}


Table 6. Preparedness Model Odds Ratios and Confidence Intervals, STUSA, 2013

\begin{tabular}{|c|c|c|c|c|}
\hline Variable & $\begin{array}{c}\text { Unadjusted } \\
\text { OR }\end{array}$ & $95 \% C I$ & $\begin{array}{c}\text { Adjusted } \\
\text { OR }\end{array}$ & $95 \%$ CI \\
\hline \multicolumn{5}{|l|}{ Risks (compared to no risk) } \\
\hline Hurricane & $1.00 *$ & 0.06-15.99 & $1.91 *$ & $0.07-20.69$ \\
\hline Earthquake & $0.44^{*}$ & $0.72-2.74$ & $0.38 *$ & $0.70-3.16$ \\
\hline Both (hurricane and earthquake) & $0.83 *$ & $0.13-5.35$ & $0.50 *$ & $0.63-3.94$ \\
\hline \multicolumn{5}{|l|}{ Population size (compared to small) } \\
\hline Medium & $1.35^{*}$ & $0.30-5.94$ & $2.22 *$ & $0.38-12.92$ \\
\hline Large & $3.33 *$ & $0.59-18.89$ & $6.27 *$ & $0.83-47.17$ \\
\hline Mega & $2.08 *$ & $0.27-15.77$ & $4.15 *$ & $0.92-43.98$ \\
\hline \multicolumn{5}{|c|}{ Jurisdiction Type (compared to non-island) } \\
\hline Island & $2.74 *$ & $0.30-25.42$ & $7.20 *$ & $0.44-116.45$ \\
\hline
\end{tabular}




\section{DISCUSSION}

Our findings failed to support our hypothesis that jurisdictions with earthquakes or hurricanes risks may have better knowledge and preparedness with regards to environmental health assessments of disaster shelters. These results were consistent even when analyzed across other characteristics such as size and type of jurisdictions. Our attempt was just to use two risk factors or types of disasters people are most familiar with or at least we thought. Perhaps our failure to show such association with only two risks was due to other reasons or motivated by other factors or experiences no assessed during this research.

For example, we know that disasters are for the most geographic events and perhaps regional analysis instead of individual jurisdictional analysis may show some differences, e.g. hurricanes can only occur in coastal states. Also, other types of disasters exist that may have greater influence in disaster readiness and knowledge as they may occur with greater frequency than hurricanes and earthquakes in jurisdictions. As a result, our approach may have been somewhat biased by thinking that only two types of disasters will drive knowledge and preparedness in jurisdictions when in fact other types of events may have influenced these activities as well. As such, other disaster researchers may want to consider evaluating other potential indicators of knowledge and preparedness. These areas may include level of funding, numbers of past disasters, or exposure to other types of disasters, e.g. wildfires, coastal flooding, landslides among others. 
Our approach also did not take in consideration financial allocation and expenditures in the area of environmental health and disaster preparedness. In an era in which many state and local programs are experiencing financial and personnel cuts, it is important to recognize those are limitations and jurisdictions may put their limited resources where there is the greatest need, outbreak response, bioterrorism and not environmental health activities like shelter assessments. However this fact does not in any way reduces and minimizes the inherent risks these jurisdictions have. As such, we need to ensure that our public health assessment teams, whether from a high risk area or supporting through mechanisms like mutual aid assistance, are adequately knowledgeable, and prepared for conducting disaster shelter assessments.

\section{CONCLUSION}

Disasters events in the last few decades have demonstrated the need for having reliable assessment methods and tools for gathering information quickly about the conditions of disaster victims. As the populations of some of these areas considered at risk for disasters continue to increase there is pressing need to have a better understanding of motivational factors in order to reduce complacency associated with training and preparedness regardless of disaster risk perspective. The time to act is now and not in a middle of major disaster or catastrophe to learn new assessments and procedures for protecting people affected in jurisdictions with known risks for disasters. 


\section{REFERENCES}

1. FEMA (Federal Emergency Management Agency) 1996. Guide for All-hazard Emergency Operations Planning. State and Local Guide 101. September 1996. Retrieved from: http://www.fema.gov/pdf/plan/slg101.pdf. Accessed February 2014.

2. Department of Homeland Security. Plan and Prepare for Disasters. Retrieved from: http://www.dhs.gov/topic/plan-and-prepare-disasters. Accessed October 2014.

3. Malilay J, Hermann M, Perrott D, Wolkin AF, Schnall AH, Podgornik MN, Cruz MA, Horney JA, Zane D, Riesman R, Greenspan JR, Thoroughman D, Anderson HA, Wells EV, Simms EF. The role of applied epidemiology methods in the disaster management cycle. American Journal of Public Health 2014;104:2092-2102.

4. NOAA (National Oceanographic \& Meteorological Administration). Hurricane Research Division. Atlantic Oceanographic \& Meteorological Laboratory. Frequently Asked Questions. Retrieved from: http://www.aoml.noaa.gov/hrd/tcfaq/A3.html Accessed February 2014.

5. NOAA. Communities: The US Population Living in Coastal Watershed Counties. Retrieved from: http://stateofthecoast.noaa.gov/population/welcome.html. Accessed January 21, 2013.

6. EPA (Environmental Protection Agency). Coastal watershed Factsheets- Oceans and coastal protection: Your Coastal Watershed. Retrieved from:

http://water.epa.gov/type/oceb/fact1.cfm. Accessed December 10, 2013.

7. Greenough G, McGeehin M, Bernard SM, Trtanj J, Riad J, Engelberg D. 2009. The potential impacts of climate variability and change on health impacts of extreme weather events in the United States. Environmental Health Perspectives 109:191-198.

8. Carpender SK, Campbell PH, Quiram BJ, Frances J, Artzberger JJ. 2006. Urban evacuations and rural America: lessons learned from hurricane Rita. Public Health Reports 121:775-779.

9. GAO. (General Accounting Office) Voluntary organizations in disasters. FEMA should more fully assess organizations mass care capabilities and update the Red Cross role in catastrophic events. GAO-08-823. 2008. Retrieved from: http://www.gao.gov/products/GAO-08-823. Accessed March 2013.

10. DHS. (Department of Homeland Security). Written testimony of FEMA Administrator Craig Fugate for a Senate Committee on Homeland Security and Governmental Affairs, Subcommittee on Emergency Management, Intergovernmental Relations, and the District of Columbia hearing titled “One Year Later: Examining the 
Ongoing Recovery from Hurricane Sandy. 2013. Retrieved from:

http://www.dhs.gov/news/2013/11/06/written-testimony-fema-administrator-senatehomeland-security-and-governmental. Accessed November 2013.

11. Personal communication with Dr. Bill Leith (USGS) about unpublished data, 2013.

12. USGS. (US Geological Survey) Earthquake Hazards Program. 2013. The Science of Earthquakes. Retrieved from: http://earthquake.usgs.gov/learn/kids/eqscience.php. Accessed December 2013.

13. USGS. Earthquake Hazards Program. 2013. Largest earthquakes by state and territory. Retrieved from: http://earthquake.usgs.gov/earthquakes/states/state_largest.php. Accessed December 2013.

14. USGS, Earthquake Hazards Program. 2013. Casualties and damage after the 1906 earthquake. Retrieved from:

http://earthquake.usgs.gov/regional/nca/1906/18april/casualties.php. Accessed November 2013.

15. The Alfred E. Alquist Seismic Safety Commission. The study of household preparedness: preparing California for earthquakes. 2009. Retrieved from: http://www.seismic.ca.gov/pub/CSSC\%200903\%20The\%20Study\%20of\%20Household\%20Preparedness.pdf. Accessed March 2014.

16. FEMA. Personal preparedness in America: findings of the 2009 Citizen Corps National Survey. 2009. Retrieved from: https://s3-us-gov-west1.amazonaws.com/dam-production/uploads/20130726-1859-250452081/2009_citizen_corps_national_survey_findings__full_report.pdf. Accessed March 2013.

17. The Sphere Project. 2011. Humanitarian charter and minimum standards in humanitarian response. 2011 Edition. Retrieved from: http://www.sphereproject.org/. Accessed March 2014.

18. FEMA. National Response Framework: Emergency Support function (ESF) Annexes. 2013. Retrieved from: http://www.fema.gov/national-preparedness-resource-library. Accessed May 2014.

19. CRS Report for Congress. T. Stafford Disaster Relief and Emergency Assistance Act: Legal Requirements for Federal and State Roles in Declarations of an Emergency or a Major Disaster. 2013. Retrieved from:

http://fpc.state.gov/documents/organization/53688.pdf. Accessed November 2013. 
20. O’Neil PD. Emergency evacuation orders: considerations and lessons from Hurricane Sandy. Journal of Emergency Management 2014;12:219-227.

21. Aghababian RV. 1992. Infectious diseases following disasters. Annals of Emergency Medicine 21:362-367.

22. Watson JT, Gayer M, Connolly MA.2007. Epidemics after natural disasters. Emerging Infectious Diseases 13:1-5.

23. CDC. Epidemiologic Notes and Reports Surveillance of Shelters after Hurricane Hugo-Puerto Rico. 1990. MMWR. 39:41-47.

24. Yee EL, Palacio H, Atmar RL, Umair S, Kilborn C, Faul M, et al. 2007. Widespread outbreak of norovirus gastroenteritis among evacuees of hurricane Katrina residing in a large "Mega Shelter” in Houston, Texas: lessons learned for prevention. Clinical Infectious Diseases 44:1032-1039.

25. CDC. Infectious disease and dermatologic conditions in evacuees and rescue workers after hurricane Katrina---multiple states, August-September 2005. 2005. MMWR 54:1-4.

25. FEMA. Functional Needs Support Services. Guidance on planning for integration of functional needs support services in general population shelters. 2010. Retrieved from: http://www.fema.gov/pdf/about/odic/fnss_guidance.pdf. Accessed October 2014.

27. Malilay J. 2005. Public health assessments in disaster settings: recommendations for a multidisciplinary approach. Prehospital and Disaster Medicine 15:167-172.

28. Hlady WG, Quenemoen LE, Armenia-Cope RR, Hurt KJ, Malilay J, Noji EK, et al. 1994. Use of a modified cluster sampling method to perform rapid needs assessment after a hurricane Andrew. Annals of Emergency Medicine 23:719-725.

29. Choudhary E, Chen TH, Martin C, Vagi S, Roth J, Keim M, et al. 2012. Public health needs assessments of Tutuila Island, American Samoa, after the 2009 tsunami. Disaster Med Public Health Preparedness 6:209-216.

30. Brodie M, Weltzioen E, Altman D, Blendon J, Benson JM. 2006. Experiences of hurricane Katrina evacuees in Houston shelters: implications for future planning. American Journal of Public Health 96:1402-1408.

31. Greenough G, Lappi MD, Hsu EB, Fink S, Hsieh Y, Vu A, et al. 2008. Burden of disease and health status among hurricane Katrina displaced persons in shelters: a population-based cluster sample. Annals of Emergency Medicine 51:426-432. 
32. Rodriguez SR, Tocco JS, Mallonee S, Smithee L, Cathey T, Bradley K. Rapid needs assessment of hurricane Katrina evacuees-Oklahoma, September 2005. 2006. Prehospital \& Disaster Medicine 21:390-395.

33. Cruz MA, Miller M, Kapil N, Kalis M. 2009. Assessing Environmental health issues in shelters during disaster operations. Abstract presented at the 2009 HHS Integrated Training Summit Web site. Retrieved from: http://www.integratedtrainingsummit.org/presentations/2009/main_training_summit/3 9_environmental_health_assessments_and_tools_utilized_in_disaster_response_even ts_-_cruz.pdf. Accessed November 2013.

34. Environmental Health Training in Emergency Response (EHTER). Retrieved from: http://www.cdc.gov/nceh/ehs/eLearn/EHTER.htm. Accessed November 2013.

35. Kalis MA, Miller MD. 2010. EHTER: where does it go from here? Journal of Environmental Health 72:38-39.

36. Beitsch L, Kodolikar S, Stephens T, Shodell D, Clawson A, Menachemi N, Brooks R. A state-based analysis of public health preparedness programs in the United States. Public Health Reports 2006;121:737-745.

37. CDC. Public health preparedness: 2012 State-by state report on laboratory, emergency operations coordination, and emergency public information and warning capabilities. 2012. Retrieved from: http://www.cdc.gov/phpr/pubs-links/2012. Accessed October 2014.

38. Cruz, MA, Rubens M., Garcia S, Malilay J, Miller MD, Levin KE, Williams OD. Prevalence, Knowledge, and preparedness for environmental health assessments in disaster shelters by US state and territorial jurisdictions: results of a 2013 STUSA survey. Unpublished data. 


\section{CHAPTER V}

ENVIRONMENTAL HEALTH DEFICIENCIES FOUND IN DISASTER SHELTERS:

A DESCRIPTIVE ANALYSIS OF STATE ENVIRONMENTAL HEALTH SHELTER

ASSESSMENT DATA AVAILABLE FROM SELECTED EVENTS

\section{ABSTRACT}

Background: Disasters shelter assessments are assessments conducted routinely to evaluate the living environment of shelter occupants with regards to hygiene and sanitations and safety. To our knowledge no research efforts had been made to describe these environmental health assessment findings using data collected during actual disaster in the US.

Methods: A call for records available on these assessments was sent to state and territorial environmental health agencies. A secondary data analysis of records available ( $n=108)$ on environmental health shelter assessments was carried out. Descriptive analysis was performed using the main domains of the current CDC tool for shelter assessments as a model. These were: facility, food, water, health and medical issues, sanitation, waste, child care area, sleeping area and companion animals.

Results: Environmental health assessments were mainly conducted for: ice storms (32\%) floods (31\%), and tornadoes (31\%). Most shelter facilities were: places of worship (26\%) or schools (22\%). The greatest numbers of environmental health deficiencies were found in: sanitation (32), facility and food service (18 and 16) issues respectively. Across 
all events, most deficiencies were found during: ice storms (58), followed by tornadoes (18) and flood events (18).

Discussion: This report paper describes the first analysis of environmental health deficiencies found in disaster shelters during disasters. The results of this pilot study highlighted potential benefits of using environmental health shelter assessments during disasters in public health preventive effort. Although the information presented here came from only one jurisdiction and results cannot be generalized, our findings, provided a snapshot of health and safety issues found in these facilities during disasters and the potential use of these assessments methods for risk management during disasters.

Conclusion: Environmental health deficiencies pose a threat to the health and safety of occupants, and more research is needed in order to evaluate the effectiveness of these disaster assessment methods in preventing illness and conditions that may pose a threat to the health of disaster victims and shelter workers. 


\section{INTRODUCTION}

Disasters are complex events and their impact is usually measured in the way they affect people’s living conditions. In the United States, emergencies and large disaster events occur almost on an annual basis affecting communities' indiscriminately. ${ }^{1}$ As a result of these events there are a number of known effects: widespread damage to the environment and to life-sustaining infrastructure, and disruption of essential services. In addition, many people are displaced: either forced out of their homes as a result of implementation of population preventive measures like evacuations; or as a result of losing their homes due to the effects of the disaster. Many of these affected people end up in disaster shelters and according to widely accepted principles of humanitarian assistance, their basic needs: security, safe food and water, adequate sheltering and access to services must be promptly assessed and met. ${ }^{2,3}$

Disaster shelter facilities come in various sizes and types. They range from small venue facilities housing a small numbers of individuals, to large and mega-facilities capable of holding thousands. Shelters provide a setting for the protection from direct effects of the event to members of a community affected, including companion animals. ${ }^{4,5}$ In the United States, major disaster shelter operations are part what is known as “mass care” activities. These are coordinated by the Federal Government, specifically, by the Federal Emergency Management Agency (FEMA). The American Red Cross (ARC) co-leads these efforts along with a number of national and local volunteer organizations. According to FEMA, in a given large disaster event up to 50-60 \% of the 
facilities in operation are managed by the ARC, and the rest by volunteer and private organizations. ${ }^{6,7,8,9}$

Public health agencies, in particular environmental health agencies, play key roles in protecting the health of people living in shelter facilities. Ideally, environmental or public health disaster teams working on these facilities need to have a basic understanding of their roles and the various environmental health issues that could pose risks to the health and safety of the shelter occupants. ${ }^{11,12}$ After disasters, there is often a presumption that outbreaks of disease would follow. ${ }^{13}$ However, the appearance of an outbreak would actually depend on a number of factors and characteristics of the affected populations. For example, access to basic needs and commodities such as safe food and water, the maintenance of adequate hygiene and sanitation, access to certain preventive services, and pre-existing or endemic communicable diseases of public health importance. $^{14}$

Disaster shelters are congregate settings and bring people together under close quarters and often austere environmental conditions. As a result, they provide an environment for potential health or injury hazards to occur. ${ }^{15}$ Similar settings such as, college dormitories, nursing homes, military barracks, and even cruise ships have all been settings with previously documented outbreaks of communicable diseases and conditions such as infestations. ${ }^{16}$ In fact, several outbreaks have been documented in shelters. For example, during the aftermath of Hurricane Hugo, the Puerto Rico Department of Health (PRDOH) reported cases of respiratory illness (R/I) and head lice in many of their shelters. Furthermore, public health surveillance efforts detected 
outbreaks of gastrointestinal illness (G/I) in 25\% of disasters shelters in operation. Following Hurricane Katrina in 2005, outbreaks of G/I and R/I were documented by several state health departments and the US Centers for Disease Control and Prevention (CDC) among shelter evacuees in shelters located in the states of Colorado, Georgia, Louisiana, Mississippi, Tennessee, and Texas. According to the CDC, G/I was the most common acute illness complaint reported among Katrina evacuees in shelters. In another, a large outbreak of methicillin resistant Staphylococcus aureus (MRSA) was also detected among children and several adults in a Texas shelter facility. ${ }^{17,18,19}$ During Hurricanes Ike and Gustav public health surveillance activities in ARC shelters revealed that the most chief complaints in most shelters involved exacerbation of chronic conditions, and acute illness which included R/I and G/I complaints. ${ }^{20}$

Disaster survivors, and those providing volunteer care for them in disaster shelters may be also at risk for illness or injury under these circumstances. ${ }^{21}$ Many survivors will arrive with their own set of special mental health, medical, mobility, and functional needs (e.g. physical, sensory, cognitive or intellectual disabilities) which could present a risk for illness or injury under disaster. ${ }^{22}$ Public health need assessments during recent disasters have consistently documented these needs and vulnerabilities. Needs assessments conducted among Hurricane Katrina evacuees in evacuation centers located in Texas, and Oklahoma shelters found that evacuees were mostly low income African-American, and more than half of them lacked health insurance. In addition, 56\% of the adults and 21\% of children in disaster shelters assessed were found to have chronic health conditions 
including acute stress disorders. ${ }^{23}$ Approximately 63\% of those interviewed also reported having a missing household member, or did not know the conditions of their homes.

Shelter workers are another group of concern. Many shelter workers are older retired members of the community with their own chronic health issues that could place them at risk for injuries, illnesses or exacerbation. ${ }^{24}$ In addition, some of the shelter workers (many of which will perform public health functions) are known to lack training on how to perform these preventive activities. ${ }^{25,26}$ These reasons highlight the importance having trained assessment teams, and operational procedures for monitoring the living environment in the disaster shelter. Documenting any deficiencies found in shelters can usually be achieved using environmental health shelter assessments tools that are currently available. ${ }^{27}$ These tools can document most deficiencies encountered in facilities (e.g. hygiene, sanitation, safety issues), and create a written record of findings to assist the public health team in documenting and prioritizing facilities, in particular those with deficiencies that may pose potential risks to occupants.

Using environmental health data for risk management in congregate setting is not new. In the past these have been used in the development of guidance pertaining to safety in food establishments such as the Food and Drug Administration Food Code which is a model used by almost all state restaurant inspection programs to tailor their food inspection programs. In addition, CDC’s Vessel Sanitation Program’s inspection system for cruise ships use the results of these environmental health inspection to enforce regulations to control communicable diseases in cruise ships. ${ }^{28,29,30,31,32,33}$ In regards to development of environmental assessment tools for shelters, in 2008 the CDC in 
collaboration with local and state public health agencies, the ARC, and one academic partner developed and subsequently released to the public environmental health assessment tool for shelters. ${ }^{34}$ Since then, many states have adopted the CDC tool, created modified versions, or used their own jurisdictional tools to assess disaster shelters. In addition over 2500 public health professionals have been trained in shelter assessments using this form as part of the CDC-sponsored Environmental Health Training in Emergency Response course. ${ }^{35}$ However, regardless of progress in this area little is known about the types of deficiencies that are found in these facilities during assessments: examination of shelter assessment data that may be available in state and territorial jurisdictions may yield an understanding of potential risks areas that may pose a health or safety risk to disaster shelter occupants.

In 2013, a two-phase project titled State and Territorial Utilization Survey Assessment or "STUSA" survey was conducted. The goals of phase one of STUSA were to assess the levels of knowledge, familiarity and preparedness for these assessments in US state and territorial jurisdictions. Of this, 55 of 56 (98\% response rate) jurisdictions targeted responded to the survey, and most reported knowledge (91\%) and reported already using or considering using these assessments (76\%) in disasters. In 2014, STUSA state and territorial participants were contacted once again and asked their interest in sharing data available on environmental health assessments conducted in disaster shelter facilities during emergencies. Our goal this time was to conduct an analysis of shelter assessment data received from jurisdictions. This report summarizes the results of the analysis of state shelter assessment data across multiple-events. 


\section{METHODS}

State and territorial jurisdictions from the original STUSA survey were contacted by email in the summer-fall of 2014 and asked to contribute data available in their jurisdictions from environmental health shelter assessments conducted during any disaster or emergency. Initially a total of 239 records were available from four different states. Approximately 216 of those shelter assessment records were received from just one state jurisdiction, and no shelter assessment data was received US territories. Our inclusion criteria required (1) using the initial assessment conducted at a facility within first 72 hours of the initial event, and (2) only one record was allowed for each facility during a particular event. Incomplete or repeated records of assessment in the same facilities were excluded.

Data from individual deficiencies documented in the forms were assigned to nine domains of interest, similar to those on the CDC Environmental Health Assessment Form for Shelters (Figure 1). These domains were: facility, food, drinking water and ice, health/medical, sanitation, solid waste, childcare area, sleeping area, and companion animals. Each domain available on the CDC tool contains additional subdomains or areas that are evaluated during the shelter assessment. The facility domain includes ten areas; the food domain includes ten areas; the drinking water and ice domain includes four areas; the health and medical domain includes three areas, the sanitation domain includes eight areas; the solid waste domain includes six areas; the childcare area domain includes seven areas; the sleeping area domain includes 5 areas; and the companion animal or pet domain included four areas. ${ }^{32}$ 


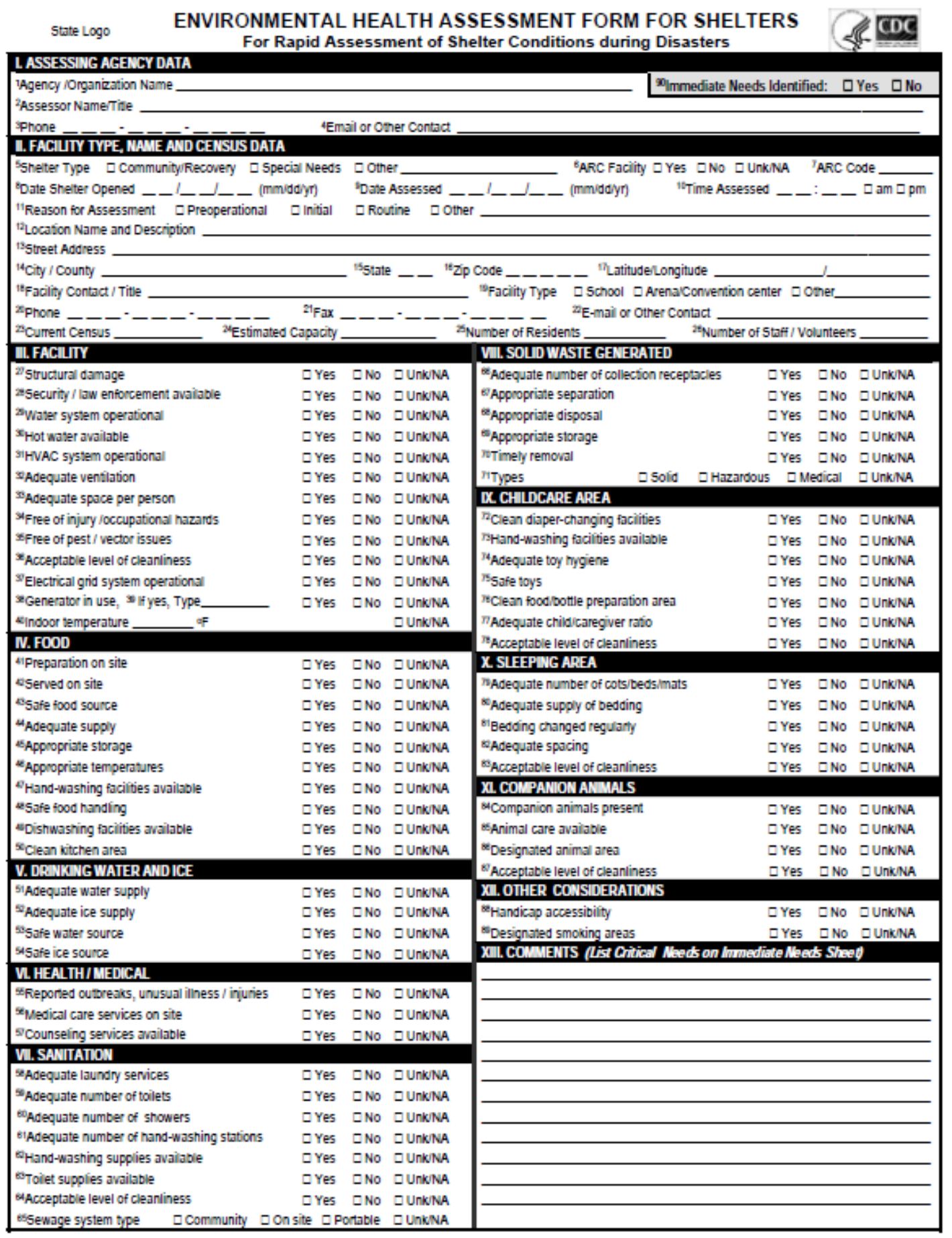

Figure 1. Centers for Disease Control and Prevention, Shelter Assessment Tool 
Our first task consisted of reviewing the consistency of data variables across all shelter forms received, there were significant differences among them. Figure 2, displays the processes used for evaluating these data sets. Our next step was to evaluate all the potential combination of variables, and domains from each jurisdictional assessment tool received to choose similar variables across all the domains. Our last step consisted of using these variables and domains to create a "model' or 'universal” shelter assessment tool that include those common variables, Figure 3. The final result was a tool that contained only four domains versus nine in the CDC tool. These were: facility; food; water; and sanitation.

There were however major differences created in the information contained on both the CDC tool and the universal form created as a result of this process. For example, the facility domain in the new form contained only 3 areas versus 10 areas contained in the CDC tool; the new food domain included only 3 vs 10 areas; the water domains included only 2 versus 4 areas. In addition, domains or subdomains areas for: health and medical, waste, childcare, sleeping area, and companion animal were not represented. As a result of this there was a decline in a number of variables for analysis. As a result, a decision was made to only analyze one large dataset that was available from a state which contained 216 shelter assessment records from various disaster events. Descriptive statistics were used to describe our findings across the various domains using IBM SPSS version 21. 


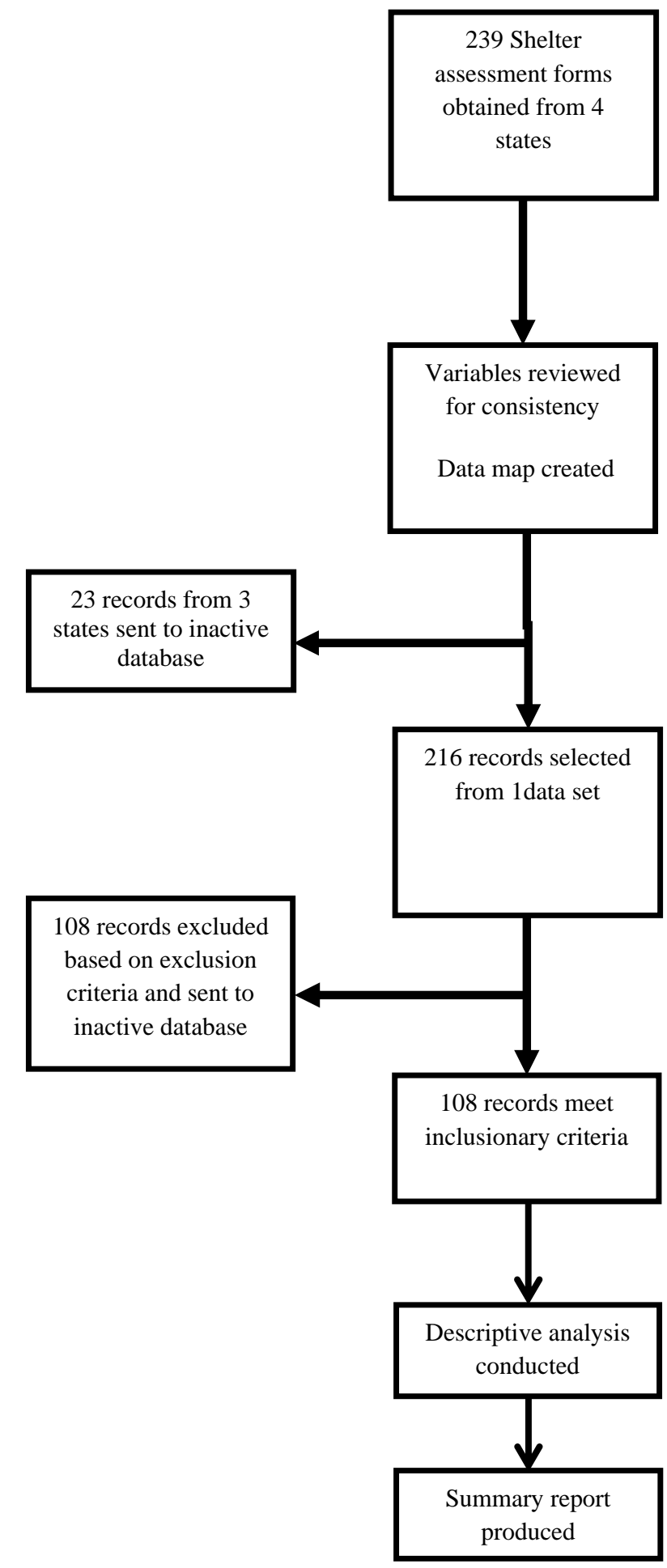

Figure 2. Flow Diagram Describing Process for Selection of Shelter Assessment Records for Analysis 


\section{Confidential}

\section{Universal Shelter Form}

Record ID

I. TYPE OF DISASTER

II. DATE ASSESSED

III. FACILITY IDENTIFICATION

1. Shelter Name

2. Street Address

3. City

4. State

5. Facility Type

If other, please specify

6. Facility Contact

7. Phone Number

8. Total Census

IV. IMMEDIATE NEEDS IDENTIFIED

A. Facility

B. Food Service

C. Water

D. Sanitation

E. Comments
Extreme Weather

Flood

Ice Storm

Tornado

Tornado

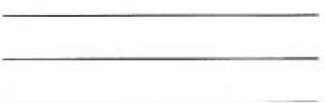

$\square$

밈

$\square$ School

Arena/Convention/Expo Center Church

$\square$ Church

$\square$ Not Identified

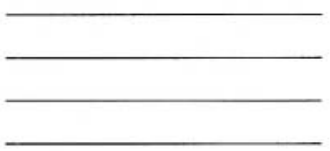

Adequate ventilation/space

Free of pests/under control

Adequate handicap accessibility

Approved/safe food source

Safe food handling/prep

Clean kitchen area

Appropriate food handling temperatures

Appropriate food storage

Dishwashing/food utensil washing sink available

Approved safe water source

Adequate water supply

Adequate hand-washing stations

Adequate hand-washing supplies

Adequate number of toilets

Adequate toilet supplies

Adequate solid waste storage/disposal

$\square$ Adequate laundry services

Figure 3. Universal Shelter Assessment Form 


\section{RESULTS}

After applying our inclusionary and exclusionary criteria a total of $n=108$ records from environmental health shelter assessments were available from events during the period of 2008 - 2014 from just one state. Table 1, describes the number of shelter assessments conducted by specific disaster or emergency event, and the specific disaster events during which these shelters were assessed. These events, all of which were weather related included: extreme cold weather storms or ice storms (32\%), floods (31\%), and tornadoes (31\%).

Table 1. Number and Percent of Shelter Assessments Conducted According to Specific Disaster Events, STUSA, 2013

\begin{tabular}{lcc}
\hline Type of Disaster & $N$ & $\%$ \\
\hline Extreme Weather & 8 & 7.4 \\
Flood & 33 & 30.6 \\
Ice Storm & 34 & 31.5 \\
Tornado & 33 & 30.6 \\
Total & 108 & 100.0 \\
\hline
\end{tabular}

Table 2, describes what types of facilities were assessed during the events. Among the most common facilities used as shelter were: places of worship (26\%) and schools (22\%). Other facilities such as military armories, hangars and other type of hardened facilities used to house displaced or person left homeless as a result of the event were also included. Large facilities like convention centers that can hold large numbers of individuals were also used (8\%). Table 3, describes the number of environmental health deficiencies found under each domain during shelter assessments. Most deficiencies were found in areas of sanitation, status or damage to the facility, and food service areas. 
Table 2. Number and Percent of Types of Shelter Facilities

Assessed during Disaster Events, STUSA, 2013

\begin{tabular}{lrr}
\hline Type of Facility & $N$ & $\%$ \\
\hline School & 24 & 22.2 \\
Church & 28 & 26.0 \\
Convention/Arena/Expo Center & 9 & 8.3 \\
Other & 38 & 35.2 \\
Missing & 9 & 8.3 \\
Total & 108 & 100.0 \\
\hline
\end{tabular}

Table 3. Number and Percent of Environmental Health Deficiencies Found by Shelter Assessment Form Domain, STUSA, 2013

\begin{tabular}{lrr}
\hline Domain & $N$ & $\%$ \\
\hline Facility & 18 & 18.8 \\
Food Service & 16 & 16.7 \\
Drinking Water & 7 & 7.3 \\
Sanitation & 25 & 26.0 \\
Solid waste & 0 & 0.0 \\
Waste Water/Sewage & 1 & 1.0 \\
Health and Medical & 11 & 11.5 \\
Children's Area & 4 & 4.2 \\
Sleeping Area & 13 & 13.5 \\
Companion Animals & 1 & 1.0 \\
Total & 96 & 100.0 \\
\hline **CDC Shelter assessment tool domains & &
\end{tabular}

The only domain area in which no deficiencies were noted was waste management. The number of environmental health deficiencies was also evaluated across the various types of disasters. According to the data the most common environmental health deficiency found was sanitation issues followed by facility and food service issues, which are shown in Table 4. The event that generated most environmental health issues were ice storms (58) followed by tornadoes (18). 
Table 4. Number of Deficiencies Found by Domain and Types of Disaster Events, STUSA, 2013

\begin{tabular}{lccccrr}
\hline Domain & $\begin{array}{c}\text { Extreme } \\
\text { Weather }\end{array}$ & Flood & $\begin{array}{c}\text { Ice } \\
\text { Storm }\end{array}$ & Tornado & $\begin{array}{c}\text { All } \\
\text { Events }\end{array}$ \\
\hline Facility & 1 & 2 & 12 & 3 & 18 & 18.75 \\
Food Service & 3 & 1 & 6 & 6 & 16 & 16.67 \\
Drinking Water & 1 & 2 & 4 & 0 & 7 & 7.29 \\
Sanitation & 2 & 5 & 15 & 3 & 25 & 26.0 \\
Solid Waste & 0 & 0 & 0 & 0 & 0 & 0.00 \\
Waste/Water/Sewage & 0 & 0 & 0 & 1 & 1 & 1.04 \\
Health and Medical & 0 & 2 & 8 & 1 & 11 & 11.46 \\
Children's Area & 0 & 0 & 3 & 1 & 4 & 4.17 \\
Sleeping Area & 0 & 1 & 9 & 3 & 13 & 13.54 \\
Companion Animals & 0 & 0 & 1 & 0 & 1 & 1.04 \\
Total & 7 & 13 & 58 & 18 & 96 & 100.0 \\
\hline **CDC Shelter assessment tool domains & & & & &
\end{tabular}

\section{DISCUSSION}

Here we attempt to describe the types of environmental health issues that are commonly found in disaster shelter during disasters. Our findings demonstrated the types of facilities that are commonly used as disaster shelters in just one particular state jurisdiction. In addition, our results help to highlight some of the most common deficiencies found under certain disaster type circumstances. To our knowledge this is the first report describing the results of the analysis of these deficiencies. However, because we only analyzed only one state shelter assessment data our results cannot be compared to other jurisdictions or generalized. We also don't know how and by whom these assessments were carried out or, the assessor's level of training, or what particular set of training or shelter standards were used for evaluating the facility. Despite the fact that our sample was relatively small, the initial process of aggregating shelter data across jurisdictions identified serious challenges that exist when trying to analyze disaster 
shelter assessment data across several jurisdictions. The amount of variability or lack of standardization of assessment tools across jurisdictions impeded a thorough analysis of these assessment data key areas of a shelter operation. From a practical and public health preparedness standpoint these concerns are valid and must be addressed promptly in the best interest of shelter operations. The potential effects in not doing so could be several: including a lack disaster situational awareness, delays in recognizing needs or gaps, and poor prioritizing of resources needed in shelters facilities.

With regard to the shelter living environment specific areas, it is important from a public health prevention standpoint to focus assessments in all areas of the facility regardless of which domains ones showed the greatest number of deficiencies. The reason is that areas found to have fewer deficiencies are as important and can still pose significant risks that maybe compounded by the austere conditions caused by most disasters to shelter occupants. Previous work in other congregate settings have documented similar environmental health concerns including issues that pose a threat of communicable disease outbreaks and conditions. ${ }^{15,17}$ For example, lack of oversight in food areas could create unsafe conditions that may lead to outbreaks capable of affecting large groups of susceptible individuals. This could results in an unwanted surge of ill individuals into damaged or overwhelmed health care facilities located in the impacted areas.

Other deficiencies in domains like daycare areas in shelters, water safety, and waste issues were not widely reported. However, any of these deficiencies have the potential to cause health issues because of the special populations involved (children) or 
spread of waterborne diseases via or vectors attracted by the unsanitary conditions. One good example of this scenario occurred during the Gulf Coats hurricanes of 2005, in which several outbreaks of gastrointestinal diseases and skin conditions were reported in facilities. ${ }^{17,18}$

With regards to the potential usefulness of shelter assessment data, we must continue to find ways to collect additional data on the results of these shelter assessments in disaster situations just like agencies due routinely for restaurants, daycare facilities or nursing homes. Potential uses of these data may include in disease and injury prevention, risk management, and risk reduction. Again, this information will be of value if gathered consistently using standard methods and tools. Otherwise the ability of researchers to conduct a thorough analysis of this information will be severally compromised or limited due to the reasons previously describes. Only then we will be in better position to fully evaluate the benefits of shelter assessment information and establish whether these activities have any effect in reducing associated morbidity and mortality and protecting the health of shelter occupants.

\section{CONCLUSION}

Environmental health professionals play an important role in safeguarding the health of all individuals even in non-disaster settings. During disasters the health status of individual maybe at risk if good levels of hygiene and sanitation are not well maintained. During this research we have limited access to data on shelter assessments and we ran into difficulties when trying to analyze data from several jurisdictions as a result we cannot assume that using these assessments may help to protect people in facilities during 
disasters. However, we are confident that over time and with additional information we will be able to demonstrate the potential benefits of using these assessments during disasters and argue for the standardization of disaster shelter assessment tools and methods. 


\section{REFERENCES}

1. Noji, E.K. The public health consequences of disasters. Prehospital and Disaster Medicine 2000;15:147-157.

2. Diekman, S.T., Kerney, S.P., O’Neil, M.E., \& Mack, K.A. Qualitative study of Homeowner's emergency preparedness: Experiences, perceptions, and practices. Prehospital and Disaster Medicine 2007;22:494-501.

3. The Sphere Project. Humanitarian Charter and Minimum Standards in Disaster Response (2011 ed.). Retrieved from: http://www.sphereproject.org/handbook/. Accessed October 2014.

4. Reischl TM, Sarigiannis AN, Tilden J. Assessing emergency response training needs of local environmental health professionals. Journal of Environmental Health 2008;71:14-19.

5. Institute of Medicine. Environmental public health. Impacts of disasters: Hurricane Katrina. 2007. The National Academies Press. Retrieved from: http://www.iom.edu/Reports/2007/Environmental-Public-Health-Impacts-of-Disasters Hurricane-Katrina-Workshop-Summary.aspx. Accessed August 2014.

6. Personal communication with Mr. Waddy Gonzalez (FEMA) 2014.

7. International Association of Assembly Managers. (2006). Mega Shelters: Planning and Activation. Retrieved from: http://www.cdphe.state.co.us/hf/emergencyplanning/masscare/MegaShelterPlanningActivation.pdf. Accessed March 2014.

8. Federal Emergency Management Agency. (2008). NRF Resource Center. Retrieved from: http://www.fema.gov/emergency/nrf/. Accessed May 2014.

9. National Volunteer Organizations Active in Disaster. Retrieved from http://www.nvoad.org/. Accessed May 2014.

10. Eldridge D, Tenkate TD. The role of environmental health in disaster management: a qualitative study of Australian experiences. Journal of Environmental Health 2008;71:31-36.

11. Reischl TM, Sarigiannis AN, Tilden J. Assessing emergency response training needs of local environmental health professionals. Journal of Environmental Health 2008;14-19. 
12. Aghababian RV. Infectious diseases following disasters. Annals of Emergency Medicine 1992;21:362-367.

13. Watson JT, Gayer M, Connolly MA. Epidemics after natural disasters. Emerging Infectious Diseases 2007;13:1-5.

14. Centers for Disease Control and Prevention. (2009). CDC Guidance for Emergency Shelters for the 2009-2010 Flu Season. Retrieved from: http://www.cdc.gov/h1n1flu/guidance/emergencyshelters.htm. Accessed June 2014.

15. Brundage JF, Scott RM, Lednar WM, Smith DW, Miller RN. Building associated risk of febrile acute respiratory disease in Army trainees. JAMA 1988;259:2109-2012.

16. Cookson ST, Soetebier K, Murray EL, Fajardo GC, Hanzlick R, Cowell A, Drenzek C. Internet-based morbidity and mortality surveillance among hurricane Katrina evacuees in Georgia. Preventing Chronic Disease 2008;5:1-7.

17. Yee EL, Palacio H, Atmar RL, Umair S, Kilborn C, Faul M, Gavahan TE, Feigin RD, Versalovic J, Neill F, Panlilio AL, Miller M, Spahr J, Glass RI. Widespread outbreak of norovirus gastroenteritis among evacuees of hurricane Katrina residing in a large "Mega Shelter" in Houston, Texas: lessons learned for prevention. Clinical Infectious Diseases 2007;44:1032-1039.

18. CDC. Infectious disease and dermatologic conditions in evacuees and rescue workers after hurricane Katrina---multiple states, August-September 2005. MMWR 2005;54(Dispatch):1-4.

19. Noe RS, Schnall AH, Wolkin AF, Podgornik MN, Wood AD, Spears J, Stanley SA. Disaster-related injuries and illnesses treated by American Red Cross Disaster Health Services during Hurricanes Gustav and Ike. Southern Medical Journal 2013;106:102108.

20. Aday LA. Health status of vulnerable populations. Annual Review of Public Health 1994;15:487-509.

21. Federal Emergency Management Agency. Guidance on planning for integration of functional needs support services in general population shelters. November 2010. Retrieved from: http://www.fema.gov/pdf/about/odic/fnss_guidance.pdf. Accessed April 2014.

22. Brodie M, Weltzioen E, Altman D, Blendon J, Benson JM. Experiences of hurricane Katrina evacuees in Houston shelters: implications for future planning. American Journal of Public Health 2006;96:1402-1408. 
23. Patton-Levine JK, Vest JR, Valadez AM. Caregivers and families in medical special needs shelters: an experience during hurricane Rita. American Journal of Disaster Medicine 2007;2:81-86.

24. Brahmbhatt D, Chan JL, Hsu EB, Mowafi H, Kirsch TD, Quereshi A, Greenough PG. Public health preparedness of post-Katrina and Rita shelter health staff. Preshospital and Disaster Medicine 2009;24:500-505.

25. Burkle FM. Sheltering the sheltered: protecting the public health and educating the workforce. Prehospital and Disaster Medicine 2009;24:506-507.

26. Malilay J, Hermann M, Perrott D, Wolkin AF, Schnall AH, Podgornik MN, Cruz MA, Horney JA, Zane D, Riesman R, Greenspan JR, Thoroughman D, Anderson HA, Wells EV, Simms EF. The role of applied epidemiology methods in the disaster management cycle. American Journal of Public Health 2014;104:2092-2102.

27. Cramer EH, Blanton CJ, Otto C. Shipshape: sanitation inspections on cruise ships. 1990-2005, Vessel Sanitation Program, Centers for Disease Control and Prevention. J Environ Health 2008; 70:15-21.

28. FDA. Food Code. US Department of Health, Public Health Service 2009. Retrieved from: http://www.fda.gov/downloads/Food/FoodSafety/RetailFoodProtection/FoodCode/Fo odCode2009/UCM189448.pdf. Accessed April 2012.

29. Irwin K, Ballard J, Grendon J, Kobayashi J. Results of routine inspections can predict outbreaks of food-borne illness: the Seattle-King County experience. American Journal of Public Health 1989; 79:586-590.

30. Cruz MA, Katz DJ, Suarez J. An assessment of the ability of routine restaurant inspections to predict food-borne outbreaks in Miami-Dade County, Florida. American Journal of Public Health 2001; 91:821-823.

31. Jones TF, Pavlin BI, LaFleur JB, Ingram L, Schaffner W. Restaurant inspection scores and food-borne disease. Emerging Infectious Diseases 2004;10:688-692.

32. Centers for Disease Control and Prevention. (2008). Emergency Preparedness and Response. CDC Shelter Assessment Tool. Retrieved from http://www.bt.cdc.gov/shelterassessment/

33. Cruz MA, Miller M, Kapil N, Kalis M. Assessing Environmental health issues in shelters during disaster operations. 2009 HHS Integrated Training Summit Web site. Retrieved from: http://www.integratedtrainingsummit.org. Accessed November 2013. 
34. Cruz MA, Rubens M, Malilay J, Garcia S, Miller MD, Levin KL, Williams OD. Prevalence, knowledge and preparedness for environmental health assessments in disaster shelters in US state and territorial jurisdictions: results of the 2013 STUSA survey. Unpublished data.

35. Personal communication with Mr. Martin Kalis (CDC) 2014. 


\section{CHAPTER VI. CONCLUSIONS}

\section{SUMMARY OF CONCLUSIONS}

During disasters there is no more important public health priority than to ensure the wellbeing of those affected by the event. ${ }^{1}$ Public health assessments in disasters include methods and tools for assessing the environmental health aspects of the living environment of disaster victims in shelters. ${ }^{2}$ The disaster shelter environment may be affected by austere conditions, and the disruption or inability to maintain regular preventive services. ${ }^{3}$ Furthermore, shelter occupants may fall into what we call vulnerable populations and their health and safety must be protected from the impending health and safety risks. ${ }^{4,5}$ Recent disasters have emphasized the need for developing standard methods for rapidly acquiring information about the needs of disaster victims during disasters. ${ }^{6}$ Health needs assessments of shelter occupants in previous disaster events have consistently documented the health, social and functional needs of shelter occupants. $^{7,8}$ Shelter workers, many of whom are older retired members and will arrive with their own sets of health issues and may pose an occupational health and safety challenge as well. ${ }^{9}$ In order to have a useful approach to prevention in order to minimize risks for injury and communicable disease threats during disasters is necessary that the shelter environment be monitored closely. Environmental health shelter assessments are relatively new approach and their use may not be widespread or widely understood. As such, we need more information in order to decide how and when these shelter methods may be more appropriate or indicated. 
Our research was divided in two main phases: a state and territorial crosssectional survey and a review of state and territorial environmental health records available from previous disasters containing data from these assessments. Our crosssectional survey documented state and territorial jurisdiction utilization of and preparedness for these disaster assessment methods. We demonstrated our willingness to explore potential motivators or indicators of knowledge and preparedness in jurisdictions at risk for certain disaster events. Although, we failed to establish an association between two disasters risks (hurricanes and earthquakes) and those outcomes we still encouraged by the fact that disasters risk may still influenced by the perception or combination of certain disaster risks or experiences that still have to be explored. We recommend that future researches may want to explore other factors such as geographic location, history or number of previous disasters, and perhaps the presence or absence of other jurisdictional operational or financial constraints.

Our results however revealed that environmental health deficiencies found in shelters during certain disasters offer potential insights into new ways for evaluating potential risks in these facilities. This information may be of great use to emergency managers, environmental health directors, shelter operators, and for public health prevention during disasters. Although our sample of state data was relatively small, this is the first documented analysis of data available in disaster shelter assessment across various disasters. At the same time our efforts documented the difficulty and challenges in aggregating this data for analysis when involving multiple jurisdictions. As such, these findings support the argument for standardization of these tools and assessments methods 
in order to avoid delays in determining the status of these facilities during regional or multiple jurisdictional events.

Our research was innovative in some aspects and many of our finding have been already presented to public health and disaster partners during recent national conferences: American Public Health Association, the National Environmental Health Association, and the National Hurricane Conference. As a result of these presentations more public health officials are aware of environmental health assessments and the potential benefits of using this information for risk management, disaster planning and response. As such, we should continue to seek ways to learn more from these experiences in order to improve the specificity and precision of these methods in anticipation of future disasters. We also need build this information across both jurisdictions and disaster events with the goal of using an evidence-based approach to better protect people affected by disasters. 


\section{REFERENCES}

1. The Sphere Project. Humanitarian charter and minimum standards in disaster response 2011 edition. Retrieved from: Available at URL:

http://www.sphereproject.org/handbook/. Accessed March 2012.

2. Malilay J, Hermann M, Perrott D, Wolkin AF, Schnall AH, Podgornik MN, Cruz MA, Horney JA, Zane D, Riesman R, Greenspan JR, Thoroughman D, Anderson HA, Wells EV, Simms EF. The role of applied epidemiology methods in the disaster management cycle. American Journal of Public Health 2014;104:2092-2102

3. Noji E. The Public Health Consequences of Disasters. Oxford Press. New York 1997.

4. Aday LA. Health status of vulnerable populations. Annual Review of Public Health 1994;15:487-509.

5. CDC. Infectious disease and dermatologic conditions in evacuees and rescue workers after hurricane Katrina---multiple states, August-September 2005. MMWR 2005;54:1-4.

6. GAO. Voluntary Organizations. FEMA should do more to fully assess organization's mass care capabilities and update the Red Cross role in catastrophic events. Report to Congressional requesters Num. GAO_08-823, September 2008. Retrieved from: http://www.gao.gov/products/GAO-08-823. Accessed February 2012.

7. Bethel JW, Foreman AN, Burke SC. Disaster preparedness among medically vulnerable populations. American Journal of Preventive Medicine 2011;40:139-143.

8. Greenough G, Lappi MD, Hsu EB, Fink S, Hsieh Y, Vu A, et al. 2008. Burden of disease and health status among hurricane Katrina displace persons in shelters: a population-based cluster sample. Annals of Emergency Medicine 51:426-432.

9. Raphael B, Singh B, Bradbury L, Lambert F. Who helps the helpers? The effects of a disaster on the rescue workers. Journal of Death and Dying 1983;14:9-20. 
APPENDICES 


\section{Appendix 1}

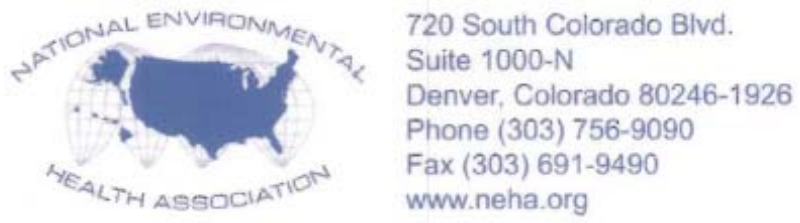

June 3, 2013

Dear Environmental Health Program Director:

The National Environmental Health Association (NEHA) is pleased to write this letter in support of the administration of the attached survey "Utilization of Environmental Health Shelter Assessments by state and Territorial Agencies during Disasters". This survey will assess jurisdictional use of these tools and methods in all US states, the District of Columbia, and Territories.

The Principal Investigator is Miguel A. Cruz, MPH, a Doctoral Student at Florida International University, Robert Stempel College of Health and Social Work in Miami, Florida. Miguel is also a strong advocate for improvement of the living environment of those affected by disasters.

Protecting the health of people in disaster shelters from environmental health hazards is one of the most important priorities during disasters. In order to better understand these risks and how they affect the health of people in disaster shelters, we need accurate and reliable data.

We believed that the findings of this survey, and his subsequent research work in this area, will help advance the understanding and awareness about environmental health issues that can affect the health and safety of one of our most vulnerable groups.

NEHA strongly supports the proposed assessment activities and we also count on your support to answer the enclosed survey when approached by Mr. Cruz.

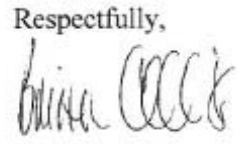

Brian Collins, President

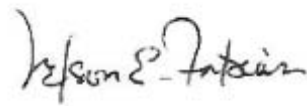

Nelson Fabian, Executive Director \& CEO 


\section{Appendix 2}

FLORIDA INTERNATIONAL UNIVERSITY

\section{Robert Stempel College of Public Health and Social Work}

May 27, 2013

\section{Dear Environmental Health Program Director:}

My name is Miguel A. Cruz, MPH. I am with the Environmental and Occupational Health Department Program at the Robert Stempel College of Public Health and Social Work, at Florida International University, Miami, Florida.

I am conducting research in disaster shelters specifically, in environmental health assessments and disaster shelters. These are assessments conducted to evaluate hygiene, sanitation, safety and other environmental health hazards.

Within the next few days you will be receive an invitation to answer a short survey about the use of environmental health assessments of shelters during disasters by your jurisdiction.

Protecting the health of people in emergency shelters is the most important priorities during disasters. Your contribution will help us in understanding how these public health assessments methods are utilized at the state and territorial level.

Please note:

- This survey will take less than 20 minutes to complete.

- Results of the data analysis will be reported ONLY in aggregate.

- NO individual identifiers will be used when reporting results.

- You are able to view and answer our on-line survey tool available NOW at: https://fiu.qualtrics.com/SE/?SID=SV_cvhVRSA3KRcMXzf

- For any questions contact me at: mcruz023@fiu.edu or call (678) 772-6930 anytime.

- A courtesy call will be made to your agency if no response is received within 14 days.

Thank you in advance for your participation!!

Miguel A. Cruz, MPH

PO BOX 49346, Atlanta, Georgia 30359

Florida International University, Miami, Florida

http://rscphsw.fiu.edu/index.html 


\section{Appendix 3 FLORIDA INTERNATIONAL UNIVERSITY Robert Stempel College of Public Health and Social Work}

\section{Dear Environmental Health Program Director or Designee:}

My name is Miguel A. Cruz, MPH. I am with the Environmental and Occupational Health Department Program at the Robert Stempel College of Public Health and Social Work, Florida International University, Miami, Florida. My area of research is Public Health and Disasters.

I am requesting your assistance in completing a short confidential survey about the use of environmental health assessments in congregate shelter facilities during disasters. These types of assessments are used to evaluate safety, hygiene, sanitation, and other environmental health hazards.

Protecting the health of people in disaster shelters from environmental health hazards is the most important priority during disasters. In order to better understand these risks and how they affect the health of people in disaster shelters we need accurate and reliable data.

Your contribution will assist us in understanding how your jurisdiction is using these assessments as well as identifying potential sources of shelter assessment data available.

Please note:

- The National Environmental Health Association supports the purpose of this survey.

- The survey takes less than 20 minutes to complete.

- Results will be reported ONLY in aggregate NO individual identifiers will be used.

- You can answer our survey available NOW on-line at: https://fiu.qualtrics.com/SE/?SID=SV_cvhVRSA3KRcMXzf

- Or scan and e-mail the completed survey to: mcruz023@fiu.edu.

- $\quad$ Or mail the completed survey to: Miguel Cruz PO Box 49346, Atlanta, Georgia 30059.

- For questions please contact me anytime at: mcruz023@fiu.edu or call (678) 772-6930.

- A courtesy call will be made to your agency if no response is received within 14 days. Thank you in advance for your participation!!

Miguel A. Cruz, MPH

PO Box 49346

Atlanta, Georgia 30359

http://rscphsw.fiu.edu/index.html 


\section{Appendix 4 FLORIDA INTERNATIONAL UNIVERSITY}

Robert Stempel College of Public Health and Social Work SURVEY ON USAGE OF ENVIRONMENTAL HEALTH SHELTER

ASSESSMENTS DURING DISASTERS

Date survey completed: Day ___ Month ___ Year

Contributing respondent contact information (Environmental Health Director or designee)

Name: Title:

State: Agency:

Telephone

Email:

The aim of this short confidential survey is to collect information regarding the use of Environmental Health Assessments of Shelter Facilities by state and territorial jurisdictions. Environmental Health Assessments of Shelter Facilities are disaster assessment activities aimed at rapidly evaluating the conditions and living environment of disaster survivors and shelter workers in congregate shelter facilities during disasters. These assessments evaluate: sanitation, hygiene, crowding, safety, environmental health hazards, and other factors known to impact the health of people. (See CDC Shelter assessments at: http://www.bt.cdc.gov/shelterassessment/)

Please note:

- $\quad$ The survey takes less than 20 minutes to complete.

- $\quad$ Results will be reported ONLY in aggregate NO individual identifiers will be used.

- You can answer our survey available NOW on-line at: https://fiu.qualtrics.com/SE/?SID=SV_cvhVRSA3KRcMXzf

- Or scan and e-mail the completed survey to: mcruz023@fiu.edu.

- $\quad$ Or mail the completed survey to: Miguel Cruz PO Box 49346, Atlanta, Georgia 30059.

- A courtesy call will be made to your agency if no response is received within 14 days.

- For any questions contact me at: mcruz023@fiu.edu or call (678) 772-6930 anytime. 


\section{KNOWLEDGE AND FAMILIARITY}

1. Is your jurisdiction knowledgeable about the concept of carrying out environmental health shelter assessments (hygiene and sanitation) of congregate shelter facilities during disasters?

[] Yes

[ ] No

[ ] UNK/NA

2. Is your jurisdiction familiar with the type of information collected using these environmental health shelter assessments tools during disasters?

[] Yes

[ ] No

[ ] UNK/NA

3. Is your jurisdiction knowledgeable about environmental health shelter assessment tools currently available for assessing congregate shelter facilities during disasters?

[ ] Yes

[ ] No

[ ] UNK/NA 


\section{PROCEDURES \& TRAINING}

\section{Are environmental health shelter assessments of congregate shelter facilities part of the activities conducted or at least considered by your jurisdiction when responding to disasters? \\ [ ] Yes (Go to question \# 5 below) \\ [ ] No (Go to question \# 4a below) \\ [ ] UNK/NA}

4a. If you answered NO to question \# 4, what are the reasons environmental health shelter assessments are not considered part of your jurisdiction's disaster response activities?

Check all that apply:

[ ] No interest

[ ] Not a disaster prone jurisdiction

[ ] Not enough staff

[ ] No prior knowledge or awareness

[ ] Prefer not to disclose

[ ] Other, please specify:
[ ] No funding

[ ] Not an area of responsibility

[ ] No training

[ ] Low event response priority

[ ] UNK/NA

5. Does your jurisdiction have operational procedures in place for conducting environmental health shelter assessments of congregate shelters during disasters?

[ ] Yes (Go to question \# 5a below)

[ ] No (Go to question \# 6 on page 4)

[ ] UNK/NA (Go to question \# 6 on page 4)

5a. If you answered YES to question \# 5, how long has it been since these assessment procedures were implemented in your jurisdiction?

[ ] Less than a year

[ ] Three to five years

[ ] UNK/NA
[ ] A year to two years

[ ] More than five years 
6. Has your jurisdiction ever received formal training on how to conduct environmental health shelter assessments of congregate shelter facilities during disasters?

[ ] Yes (Go to question \# 6a below)

[ ] No (Go to question \# 7 below)

[ ] UNK/NA (Go to question \# 7 below)

6a. If you answered YES to question \# 6, which entity or entities provided the environmental health shelter assessment training? Check all that apply:

$\begin{array}{lr}\text { [ ] American Red Cross } & \text { [ ] Local/State Emergency Management } \\ \text { [ ] Faith Base Organization } & \text { [ ] Other Non-Governmental Organization } \\ \text { [ ] Private Contractor } & \text { [ ] CDC *EHTER Course } \\ \text { [ ] Military Organization } & \text { [ ] Local or State Public Health Agency } \\ \text { [ ] UNK/NA } & \text { [ ] Other, please specify: }\end{array}$

(*EHTER=Environmental Health Training in Emergency Response, see:

http://www.cdc.gov/nceh/ehs/eLearn/EHTER.htm)

7. What is the role or roles of your jurisdiction in regards to implementation of environmental health shelter assessments of congregate shelter facilities during disasters? Check all that apply:

[ ] Training staff/assessors

[ ] Oversight of assessment activities

[ ] Provide staffing for assessments

[ ] UNK/NA
[ ] Conducting the assessments

[ ] Planning the assessments

[ ] Providing logistics support

[ ] Other, please specify: 


\section{UTILIZATION OF ASSESSMENT TOOLS}

\section{Does your jurisdiction currently have an environmental health assessment tool or form available for assessing congregate shelters during disasters?}

[ ] Yes (Go to question \# 8a below)

[ ] No (Go to question \# 9 on page 6)

[ ] UNK/NA (Go to question \# 9 on page 6)

8a. If you answered YES to question \# 8, which environmental health shelter assessment tool or form has been designated for use by your jurisdiction during a disaster? Check all that apply:

[ ] Our own jurisdictional environmental health shelter assessment tool

[ ] The Centers for Disease Control and Prevention (CDC) Environmental Health

Assessment Form for Shelters. Available at: http://www.bt.cdc.gov/shelterassessment/)

[ ] A modified version of the CDC shelter assessment tool

[ ] UNK/NA

[ ] Other:

8b. If a jurisdictional environmental health shelter assessment tool is available or will be available, for what types of shelter assessments will the tool be intended? Check all that apply:

[ ] Shelters Pre-operational/occupancy [ ] Normal or routine shelter assessments

[ ] Responses to outbreaks in a shelter [ ] Response to shelter sanitary complaints

[ ] UNK/NA

[ ] Other, please specify:

8c. Has your jurisdiction ever used or deployed the jurisdictional environmental health assessments tool to assess congregate shelter facilities?

[ ] Yes (Go to question \# 8d below)

[ ] No (Go to question \# 9 on page 6)

[ ] UNK/NA (Go to question \# 9 on page 6) 
8d. If you answered YES to question \# 8c, please specify for which type of assessment activities the jurisdictional environmental health shelter assessments tool was previously used? Check all that apply:

[ ] Actual emergency/disaster events

[ ] Training assessment teams or workers

[ ] UNK/NA
[ ] Exercise/disaster drill

[ ] Pre-disaster assessments of facilities

[ ] Other, please specify:

8e. If the jurisdictional environmental health shelter assessment tool was used previously for an actual emergency/disaster event or events, can you specify for what type (s)? Check all that apply:
[ ] Flood
[ ] Hurricane
[ ] Tornado
[ ] Wildfire
[ ] Winter Storm
[ ] Chemical
[ ] Mass gathering
[ ] Extreme Heat
[ ] Extreme Cold
[ ] Radiation
[ ] Biological Event
[ ] UNK/NA

[ ] Other, please specify:

8f. What method is used or will be used for collecting information using the jurisdictional environmental health shelter assessment tool? Check all that apply:

[ ] Paper

[ ] Computer device

[ ] Camera

[ ] UNK/NA
[ ] Handheld electronic device (iPad)

[ ] Digital pen

[ ] Video recorder

[ ] Other, please specify:

\section{Are you aware that the CDC has developed an Environmental Health Assessment Form}

for Shelters during disasters? Available at: http://www.bt.cdc.gov/shelterassessment/)

[ ] Yes (Go to question \# 9a on page 7)

[ ] No (Go to question \# 10 on page 7)

[ ] UNK/NA (Go to question \# 10 on page 7) 
9a. If you answered YES to question \# 9, has your jurisdiction ever used the CDC Environmental Health Assessment Form for Shelters?

[ ] Yes (Continue with question \# 9b below)

[ ] No (Go to question \# 10 on page 8)

[ ] UNK/NA (Go to question \# 10 on page 8)

9b. If you answered YES to question 9a, please specify for which types of activities the CDC Environmental Health Assessment Form for Shelters was used. Check all that apply:
[ ] Actual emergency/disaster events
[ ] Exercise/disaster drill
[ ] Training assessment teams or workers
[ ] Pre-disaster assessments of facilities
[ ] UNK/NA
[ ] Other, please specify:

9c. If the CDC Environmental Health Assessment Form for Shelters was used previously for an actual emergency/disaster event or events can you specify for what type (s)? Check all that apply:
[] Flood
[ ] Hurricane
[ ] Tornado
[ ] Wildfire
[ ] Winter Storm
[ ] Chemical
[ ] Mass gathering
[ ] Extreme Heat
[ ] Extreme Cold
[ ] Radiation
[ ] Biological Event
[ ] UNK/NA

[ ] Other, please specify:

9d. What method is used, or will be used, for collecting the information using the CDC Environmental Health Assessment Form for Shelters? Check all that apply:

[ ] Paper

[ ] Computer device

[ ] Camera

[ ] UNK/NA
[ ] Handheld electronic device (iPad)

[ ] Digital pen

[ ] Video recorder

[ ] Other, please specify: 
9e. Did the CDC Environmental Health Assessment Form for Shelters meet your jurisdictional emergency response needs?

$$
\begin{aligned}
& \text { [ ] Yes } \\
& \text { [ ] No } \\
& \text { [ ] UNK/NA }
\end{aligned}
$$

10. In general, how useful does your jurisdiction finds conducting environmental health assessments of congregate shelter facilities during disasters using either type of forms?
[ ] Very useful
[ ] Somewhat useful
[ ] Not useful
[ ] UNK/NA 


\section{PARTNER PARTICIPATION IN PLANNING AND EXERCISES}

11. Does your jurisdiction participate in disaster planning with shelter agencies or other mass care partners?

[ ] Yes (Go to question \# 11a below)

[ ] No (Go to question \# 12 below)

[ ] UNK/NA (Go to question \# 12 below)

11a. Please specify which planning agencies and partners. Check all that apply:

$\begin{array}{lll}\text { [ ] American Red Cross } & \text { [ ] Emergency management } & \text { [ ] Faith based } \\ \text { [ ] Military } & \text { [ ] Private sector } & \text { [ ] Academic } \\ \text { [ ] Hospitals } & \text { [ ] Social Services } & \text { [ ] Mental health } \\ \text { [ ] Animal/pet services } & \text { [ ] Law enforcement } & \text { [ ] UNK/NA } \\ \text { [ ] Other, please specify: } & & \end{array}$

12. Does your jurisdiction participate in any disaster exercises or disaster drills with shelter agencies or other mass care partners?

[ ] Yes (Go to question \# 12a below)

[ ] No (Go to question \# 13 on page 10)

[ ] UNK/NA (Go to question \# 13 on page 10)

12a. Please specify which exercise or disaster drill agency or partners: Check all that apply:

$\begin{array}{lll}\text { [ ] American Red Cross } & \text { [ ] Emergency management } & \text { [ ] Faith based } \\ \text { [ ] Military } & \text { [ ] Private sector } & \text { [ ] Academic } \\ \text { [ ] Hospitals } & \text { [ ] Social Services } & \text { [ ] Mental health } \\ \text { [ ] Animal/pet services } & \text { [ ] Law enforcement } & \text { [ ] UNK/NA } \\ \text { [ ] Other, please specify: } & & \end{array}$




\section{SURVEY FEEDBACK}

13. Would you be interested in knowing the results of this survey?

[ ] Yes (Please provide your information on question 14)

[ ] No

[ ] UNK/NA

14. Please provide your contact information. A summary of the results will be e-mailed to the address provided below.

Name:

Email

15. Additional comments:

Thank You for completing the survey! 


\title{
Appendix $5 \quad$ Florida International University \\ Robert Stempel College of Public Health and Social Work
}

\author{
SCRIPT FOR CONTACTING JURISDICTIONS THAT HAVE NOT RESPONDED TO \\ THE SURVEY
}

Hi Dr. /Mr. /Ms. my name is

I am assisting Mr. Miguel Cruz a doctoral student at Florida International University with his research in the area of environmental health and disaster shelters. Is this a good time for us to talk?

I am just following up with you as we have not yet received a completed survey on about environmental health shelter assessment usage that was mailed to you two weeks ago.

If YES: Ok is there a reason why you did not complete the survey, can I help clarify anything about the survey purpose or questions for you?

If YES: provide clarification needed, also reassure that this information is confidential and that no personal, agency or state identifiers will be used.

If NO: Ok you have a question or need an extra copy of the survey do not hesitate to contact me at or by email at any time.

We would like to move forward with this important disaster research project.

Thanks again for taking the time to participate in this survey! 


\section{Appendix 6}

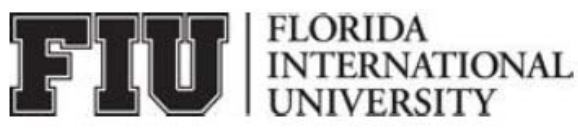

Office of Research Integrity Research Compliance, MARC 270

\section{MEMORANDUM}

To:

Dr. Oren Williams

CC:

From:

File

Date:

Maria Melendez-Vargas, MIBA, IRB Coordinator

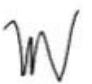

Protocol Title: $\quad$ "A State and Territorial Survey Regarding Knowledge and Utilization of

Environmental Health Shelter Assessments during Disasters, and a

Secondary Analysis of Available Shelter Assessment Data"

The Florida International University Office of Research Integrity has reviewed your research study for the use of human subjects via the Exempt Review process.
IRB Protocol Exemption \#:
IRB-13-0179
IRB Exemption Date:
$05 / 14 / 13$
TOPAZ Reference \#:
100813

As a requirement of IRB Exemption you are required to:

1) Submit an Event Form and provide immediate notification of:

- Any additions or changes in the procedures involving human subjects.

- Every serious or unusual or unanticipated adverse event as well as problems with the rights or welfare of the human subjects.

2) Submit a Project Completion Report Form when the study is finished or discontinued.

Special Conditions: N/A

For further information, you may visit the IRB website at http://research.fiu.edu/irb. 
VITA

\section{MIGUEL ANGEL CRUZ}

1987-1990

1994-1997

2008-Present

$1985-1990$

$1991-1993$

$1993-1994$

$1994-1999$

1999-Present
BS, Business Administration

Mount Saint Mary College

Newburgh, New York

MPH Public Health, Epidemiology

Florida International University

Miami, Florida

Doctoral Candidate, Environmental and Occupational Health Florida International University

Miami, Florida

Medical Specialist

United States ARMY

STD/HIV Program Disease Intervention Specialist

Pinellas County Health Department

St. Petersburg, Florida

Public Health Advisor

National Center for HIV, STD and TB Prevention

Centers for Disease Control and Prevention

Miami, Florida

Epidemiologist and Surveillance Officer

Office of Epidemiology and Communicable Disease Control

Miami-Dade County Health Department

Miami, Florida

Senior Health Services Officer

Office of Environmental Health Emergencies

Centers for Disease Control and Prevention

Atlanta, Georgia 


\section{PUBLICATIONS}

CDC. Exposures to Discarded sulfur Mustard Munitions-Mid-Atlantic and New England States 2004-2012. MMWR 2013;62:315-316

Cruz MA, Burger R, Keim M. The First 24 Hours of the World Trade Center Attacks of 2001- the Centers for Disease Control and Prevention Emergency Phase Response. Prehospital and Disaster Medicine 2007;22:473-477

Cruz MA, Hawk NE, Poulet C, Rovira J, Rouse E. Public Health Incident Management: Logistical and Operational Aspects of the 2009 Initial Outbreak of H1N1 Influenza in Mexico. Accepted for publication by Journal of Emergency Management

Cruz MA, Katz DJ, Suarez JA. An assessment of the ability of routine restaurant inspections to predict food-borne outbreaks. American Journal of Public Health. 2001;91:821-823

Cruz MA, Keim M, Gonzalez R, Valencia A, Schier J, Telfer JL. Organizational and Command Aspects for Coordinating the Public Health Response to an Outbreak of Acute Renal Failure, Republic of Panama 2006. Prehospital and Disaster Medicine 2011;26:217-223

Influenza A-Florida and Tennessee, July-August 1998, and Virologic Surveillance of Influenza, May-August 1998. MMWR 1998;47:756-759

Katz DJ, Cruz MA, Trepka MJ, et al. An outbreak of typhoid fever in Florida associated with an imported frozen fruit. Journal of Infectious Diseases 2002;186:234-239

Malilay, J, Heumann M, Perrotta DM, Funk A, Wolkin A, Schnall AH, Podgornik MN, Cruz MA, Horney JA, Zane D, Roisman R, Greenspan JR, Thoroughman D, Anderson HA, Wells EV, Simms E. The Role of Applied Epidemiology Methods in the Disaster Management Cycle. American Journal of Public Health 2014;104:2092-2102

Outbreaks of Group B Meningococcal Disease-Florida, 1995 and 1997. MMWR 1998;47:833-837

Tropical Storm Allison rapid needs assessment--Houston, Texas. MMWR 2002;51:365369 